Article

\title{
Catalytic Pyrolysis of Aliphatic Carboxylic Acids into Symmetric Ketones over Ceria-Based Catalysts: Kinetics, Isotope Effect and Mechanism
}

\author{
Tetiana Kulik ${ }^{1, *(\mathbb{D})}$, Borys Palianytsia ${ }^{1}$ and Mats Larsson ${ }^{2}$ (D) \\ 1 Chuiko Institute of Surface Chemistry, NAS of Ukraine, 17 General Naumov Str., 03164 Kyiv, Ukraine; \\ borys.palianytsia@gmail.com \\ 2 Department of Physics, AlbaNova University Center, Stockholm University, SE-106 91 Stockholm, Sweden; \\ mats.larsson@fysik.su.se \\ * Correspondence: tanyakulyk@i.ua; Tel.: +38-044-422-9676
}

Received: 29 November 2019; Accepted: 21 January 2020; Published: 3 February 2020

\begin{abstract}
Ketonization is a promising way for upgrading bio-derived carboxylic acids from pyrolysis bio-oils, waste oils, and fats to produce high value-added chemicals and biofuels. Therefore, an understanding of its mechanism can help to carry out the catalytic pyrolysis of biomass more efficiently. Here we show that temperature-programmed desorption mass spectrometry (TPD-MS) together with linear free energy relationships (LFERs) can be used to identify catalytic pyrolysis mechanisms. We report the kinetics of the catalytic pyrolysis of deuterated acetic acid and a reaction series of linear and branched fatty acids into symmetric ketones on the surfaces of ceria-based oxides. A structure-reactivity correlation between Taft's steric substituent constants Es* and activation energies of ketonization indicates that this reaction is the sterically controlled reaction. Surface $\mathrm{D}_{3-\mathrm{n}}$-acetates transform into deuterated acetone isotopomers with different yield, rate, $\mathrm{E}^{\neq}$, and deuterium kinetic isotope effect (DKIE). The obtained values of inverse DKIE together with the structure-reactivity correlation support a concerted mechanism over ceria-based catalysts. These results demonstrate that analysis of Taft's correlations and using simple equation for estimation of DKIE from TPD-MS data are promising approaches for the study of catalytic pyrolysis mechanisms on a semi-quantitative level.
\end{abstract}

Keywords: carboxylic acids upgrading; ketonization; deuterated acetic acid; acetone D-isotopomers distribution; H/D exchange; inverse deuterium kinetic isotope effect; kinetic parameters; activation energy; catalytic pyrolysis of biomass; bio-oil

\section{Introduction}

Catalytic pyrolysis can effectively convert second-generation feedstocks (lignocellulose, waste oils, fats, algae, agricultural and forest residues, etc.) into bio-oil or pyrolysis oil [1-7]. The potential for the use of biomass resources of second-generation feedstocks in Europe is very high [8]. At the same time, the cost of second-generation raw materials is low [8]. One of the major components of bio-oil [1-7,9-14] is organic acids. Currently, some of them, including acetic, valeric, levulinic ( $\gamma$-ketovaleric acid), 2,5 furan dicarboxylic acids, etc., are considered as key-building platforms in biomass conversion technologies $[1-7,12,14]$. The upgrading of bio-derived carboxylic acids has great economic, social and environmental advantages compared with the traditional use of fossil hydrocarbon resources.

The ketonization reaction, or ketonic decarboxylation is one of the attractive ways to convert carboxylic acids into sustainable biofuels and valuable industrial products with high added value [15-23]. Ketonization provides for the formation of a new C-C bond in one step, preserves the initial functional group $\mathrm{C}=\mathrm{O}$, and significantly reduces the oxygen content in the molecule 
due to decarboxylation and dehydration. In addition, the carbon chain almost doubles as a result of the symmetric ketone formation. The obtained ketones can be upgraded by catalytic hydrogenation/dehydration to liquid long-chain hydrocarbons [12,14].

Despite the close attention to the ketonization reaction, last year's publications [15-18], including numerous studies and reviews $[16,17,19-23]$ suggested that the mechanism of this reaction is not completely clear. Over the past few decades, several basic mechanisms of this reaction have been proposed [19-41]: (i) free-radical mechanism [24], (ii) direct concerted mechanism [20,25], (iii) mechanism involving an acyl intermediate [26], (iv) ketene based mechanisms [27-29], (v) and a beta-keto-acid-intermediate based mechanisms [30-35] (Scheme 1). The free-radical mechanism, the acyl-based mechanism, and ketene-based mechanism involve the participation of free radicals, acylium cation and ketene species as key intermediates of ketonization, respectively. The concerted mechanism was proposed by Rand et al. [25] for ketonization of adipic and 2,2,5,5-tetramethyladipic acids. This mechanism involves (a) decarboxylation with carbanion formation, (b) nucleophilic attack of carbanion with C-C bond formation, and (c) formation of ketone and a hydroxide anion (Scheme 1).

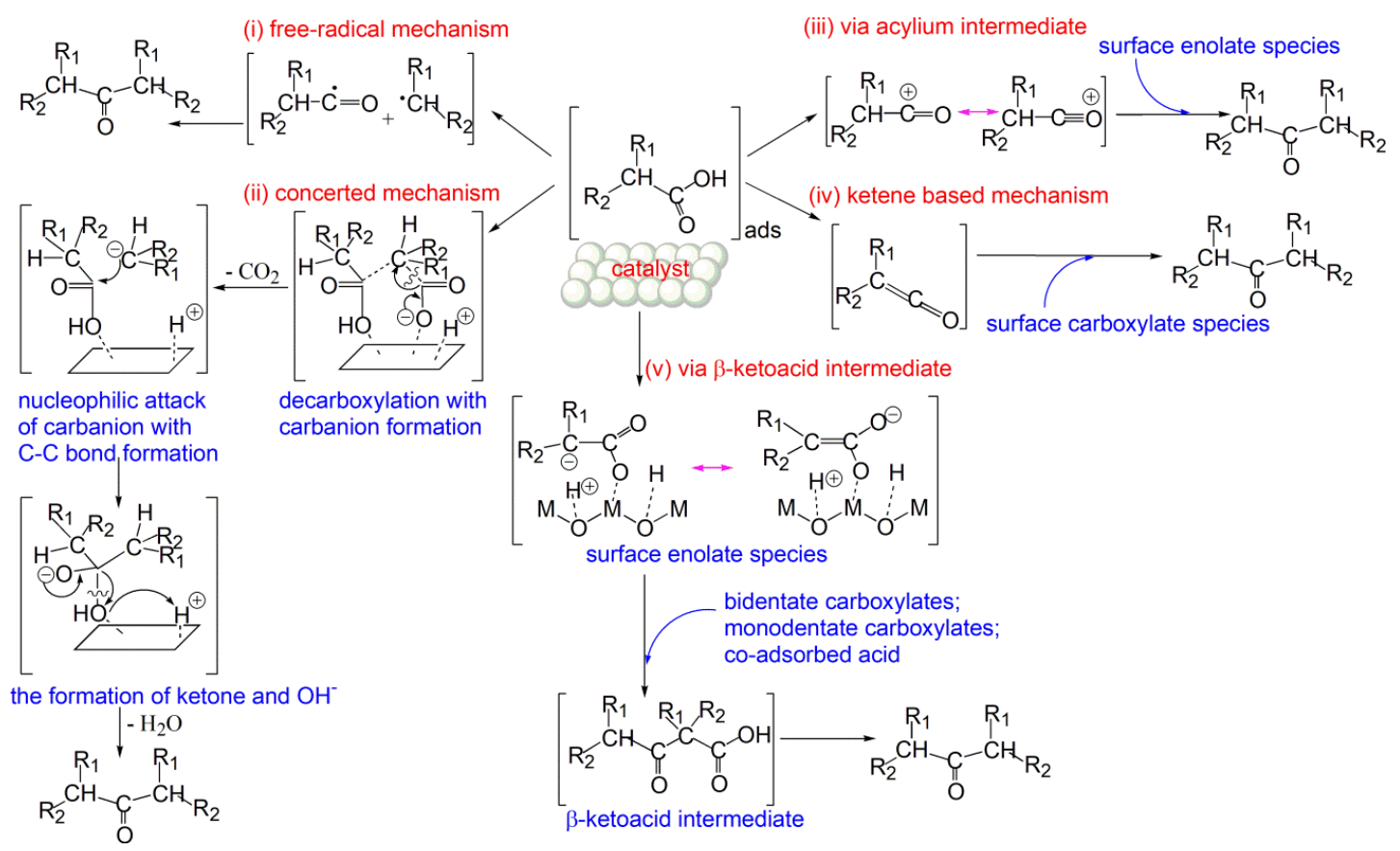

Scheme 1. Simplified schemes of possible ketonization mechanisms and their key intermediates.

At the moment, the beta-keto-acid-intermediate-based mechanism is considered the most plausible [19,30-34,37,39]. The last two mechanisms require a stage of enolization with the elimination of hydrogen in the alpha position to the carboxyl group [19,30-34]. Two basic pieces of evidence are used to confirm mechanisms involving enolization. The first evidence is the presence of isotope exchange of D-H in the alpha position to the carboxyl group on the surface of the catalysts [28,29] (Scheme 2). On this basis, it is concluded that alpha hydrogen atoms take part in the reaction. The second proof is that a symmetric ketone pivalone is not formed from pivalic acid $\left.\left(\mathrm{CH}_{3}\right)_{3} \mathrm{C}-\mathrm{COOH}\right)[28,30,35]$. It was postulated that the reason for the lack of ketonization of pivalic acid is the absence of $\alpha$-hydrogen, which excludes enolization, so ketonization is impossible [19,30,33]. However, this fact may be due to the steric effect of the substituents at the reaction center in the transition state (TS) for pivalic acid. Accordingly, it was assumed that enolisation is the rate-limiting step of the ketonization reaction. 


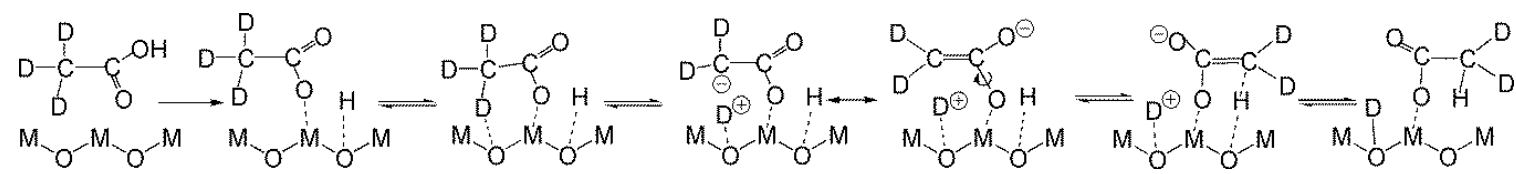

Scheme 2. H/D exchange and enolization on the surface of the catalyst.

However, on the basis of a detailed kinetic analysis [33], quantum chemical calculations [32], and an investigation of the isotopic effect [26,36], it was shown that enolization is not a rate-limiting stage. Rather the loss of the $\mathrm{CO}_{2}$ or the formation of a new C-C bond are the likely rate-determining steps $[26,32,33,36]$. Despite the enormous efforts spent on the establishment of the mechanism of this reaction, kinetic studies, isotope effect studies [26,27,36], quantum chemical calculations [30-33,36], studies of cross-ketonization reactions [28,30,33,38], ${ }^{13} \mathrm{C} /{ }^{12} \mathrm{C}$ exchange studies [34], H/D exchange studies on the catalyst surfaces [28,29,39], experiments with ${ }^{13} \mathrm{C}$-labeled acetic acids [28,33,34], Fourier Transform Infrared Spectroscopy FT-IR studies [36,37,39-41], etc., the question of establishing the full details of the ketonization reaction mechanism is still not completely closed [39]. However, linear free energy relationships (LFERs) have never been applied to study of the mechanism of ketonization. LFER is a very informative experimental approach because it can give information about the TS and the reaction mechanism on a semiquantitative basis [42,43]. Therefore, in our work, we decided to apply three of the most important experimental methods [42] to establish the mechanism of this reaction over ceria-based catalysts [44], which were not used or insufficiently used in previous works: 1) kinetic study and analysis of kinetics $\left.\left(n, T_{\max }, E^{\neq}, v_{0}, d S^{\neq}\right), 2\right)$ analysis of substituent effects (Taft plots) or LFERs between activation free energies change induced by substituents and the steric, the electron donating or electron withdrawing characteristics of the substituent and 3) study of the magnitude and the origin of deuterium kinetic isotope effect (DKIE).

The novelty of this study is due to the fact that using the LFERs principle, we obtained structure-reactivity correlation between Taft's steric substituent constants Es* and activation energies of ketonization, and evaluated the contribution of the electronic and steric effects of the substituents for a wide reaction series of carboxylic acids (acetic, propionic, butyric, isobutyric, valeric, pivalic, hexanoic, heptanoic, nonanoic, octanoic, decanoic). In addition, a novel simple approximate equation was proposed for a quick estimate of the DKIE from temperature-programmed desorption mass spectrometry (TPD-MS) data. The values of inverse DKIE of the formation of a series of acetone D-isotopomers have been obtained using this simple equation. The obtained values of the inverse DKIE allowed us to get new physical insights about the sterically controlled mechanism of catalytic pyrolysis of aliphatic carboxylic acids into symmetric ketones over ceria-based catalysts.

\section{Results and Discussion}

\subsection{Kinetic Study}

It is well known that on the surfaces of various oxide catalysts, different pathways of the conversion of aliphatic acids may take place [18,44-46] (Scheme 3). Depending on the surface properties of the catalyst, reactions can occur such as ketenization, ketonization, decarboxylation, decarbonylation, cracking, reduction to aldehydes, and others. 


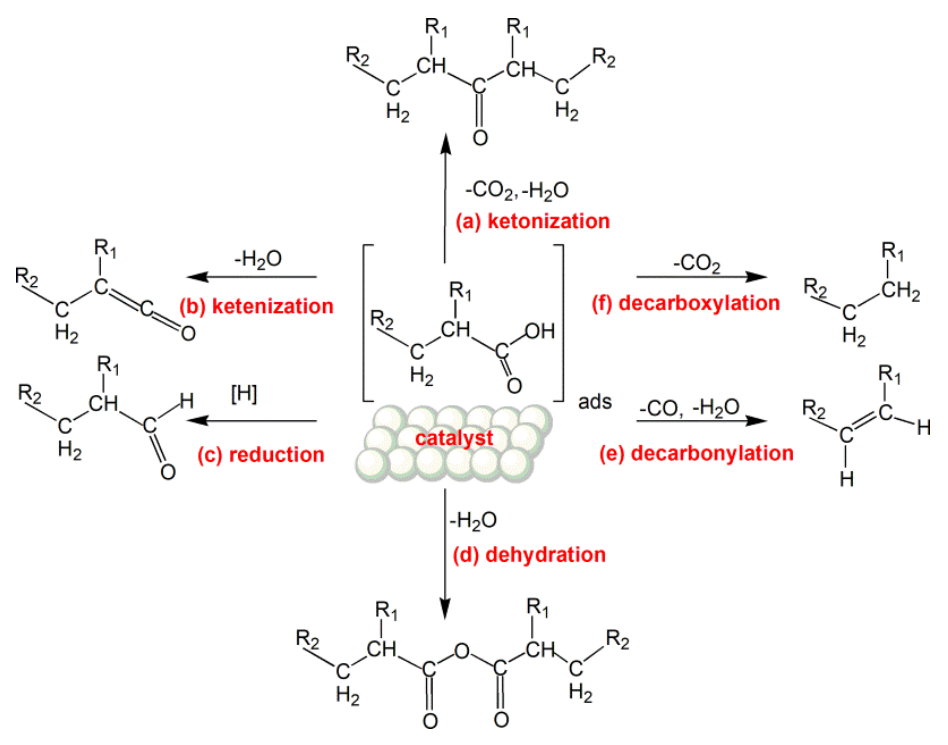

Scheme 3. The possible pathways of the conversion of aliphatic acids on the surfaces of oxide catalysts.

As was previously established [43,47-49], the ketenization reaction (pathway b, Scheme 3) proceeds on the silica at $300-450{ }^{\circ} \mathrm{C}$ with a high level of selectivity. Ketenes formation has also been observed over $\mathrm{Al}_{2} \mathrm{O}_{3} / \mathrm{SiO}_{2}, \mathrm{TiO}_{2} / \mathrm{SiO}_{2}[41]$ and aluminosilicates due to the presence of Brönsted acid sites on their surfaces [50]. Cinnamic acids on the silica surface transform into corresponding ketenes, vinyl- and acetylene-benzenes via three parallel pathways b, e and f: ketenization, decarboxylation, and decarbonylation, [51-53]; whereas over the nanoceria surface, only the decarboxylation (f) takes place [54]. A comparative study [41] of pyrolytic decomposition of valeric acid over $\mathrm{SiO}_{2}, \mathrm{Al}_{2} \mathrm{O}_{3}$, $\mathrm{CeO}_{2} / \mathrm{SiO}_{2}, \mathrm{Al}_{2} \mathrm{O}_{3} / \mathrm{SiO}_{2}$, and $\mathrm{TiO}_{2} / \mathrm{SiO}_{2}$ catalysts showed that propylketene forms on the surfaces of all these oxides except for $\mathrm{CeO}_{2} / \mathrm{SiO}_{2}$. The formation of both ketene and ketone was observed on the surface of $\mathrm{Al}_{2} \mathrm{O}_{3}$. The ceria-based catalyst converted valeric acid into dibutylketone most efficiently in the investigated series of oxides due to the presence of basic sites on its surface [41]. As was noted earlier [40], ceria is the most basic oxide in the series of oxides $\mathrm{CeO}_{2}, \mathrm{TiO}_{2}$, and $\mathrm{Al}_{2} \mathrm{O}_{3}$.

The acid-base and redox properties of ceria-based materials have been extensively investigated because the unique catalytic activity enables ceria to catalyze a variety of organic reactions [55-58]. The surface of ceria is characterized by very low Lewis and Brönsted acid site density and weak acid strength [39], while at the same time extremely high density [59] of strong Lewis-base sites [60], which interact with carboxylic acids to form different types of carboxylates (monodentate, bidentate: chelate and bridge) $[40,41,61]$. Subsequent transformation of the surface carboxylates leads to the formation of ketones [37,40,41,61].

The main pyrolysis products of aliphatic carboxylic acids on the $\mathrm{CeO}_{2} / \mathrm{SiO}_{2}$ surface are the corresponding ketones and $\mathrm{CO}_{2}$. The typical TPD-MS data of the catalytic ketonization of aliphatic carboxylic acids are presented in Figure 1A,B with the example of propionic acid. Figure 1A,B show the mass spectrum and TPD curves obtained during the catalytic pyrolysis of propionic acid immobilized on the $\mathrm{CeO}_{2} / \mathrm{SiO}_{2}$ surface. The TPD profiles of the molecular ion of the ketonization product (diethyl ketone or 3-pentanone) with $\mathrm{m} / \mathrm{z}=86$ and its fragment ions with $\left.\mathrm{m} / z=72 \mathrm{C}_{2} \mathrm{H}_{5} \mathrm{COCH}_{2}^{+}\right), 57\left(\mathrm{C}_{2} \mathrm{H}_{5} \mathrm{CO}^{+}\right)$, and $29\left(\mathrm{C}_{2} \mathrm{H}_{5}{ }^{+}\right)$reflect the shape of each other (Figure 1B). These ions are present in the spectra at the temperature of the maximum rate of the 3-pentanone formation, Figure 1A. It is known that ketonization is always accompanied by the release of water and $\mathrm{CO}_{2}$. Intensive decarboxylation accompanying the formation of the corresponding symmetrical dialkyl ketone is observed during propionic acid pyrolysis (Figure 1A,B) and all studied acids (C2-C10), except pivalic acid. As was previously established $[19,35]$, and also observed it in this work, pivalic acid forms two other major products, isobutene and 2-dimethyl-4-methyl-3-pentanone (Table 1). 

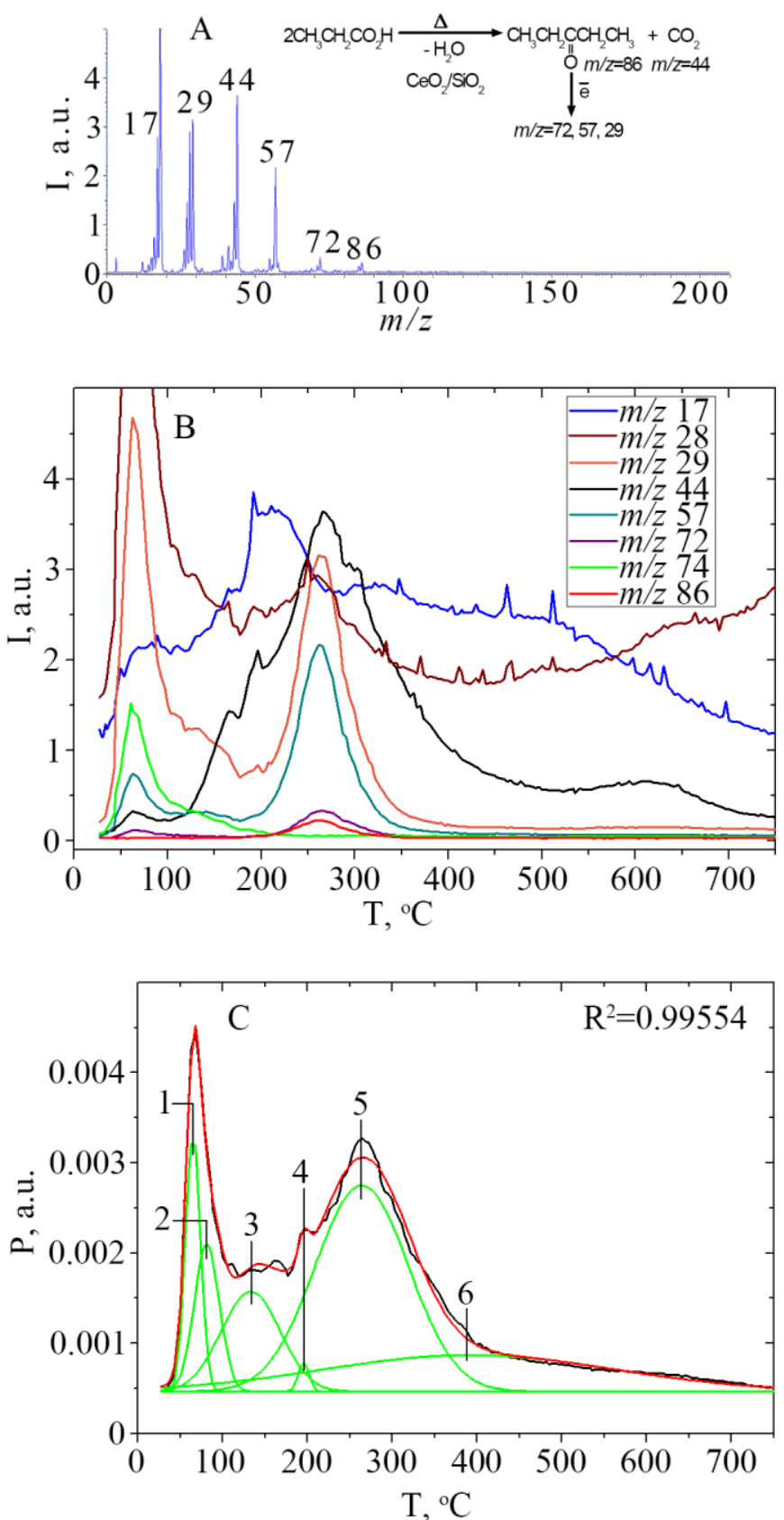

Figure 1. Catalytic pyrolysis of propionic acid supported on the nanocomposites $\mathrm{CeO}_{2} / \mathrm{SiO}_{2}$ with low amount of $\mathrm{CeO}_{2}(\mathrm{CeSi})$ surface $\left(0.6 \mathrm{mmol} \mathrm{g}^{-1}\right)$. (A) Mass-spectrum of pyrolysis products at 265 ${ }^{\circ} \mathrm{C}$, obtained after electron impact ionization. (B) temperature-programmed desorption curves (TPD curves) of the molecular ion of propionic acid with $\mathrm{m} / \mathrm{z}=74$ and its fragment ions with $\mathrm{m} / \mathrm{z}=72,44$, $29,28,17$ attributed to the desorption of the physically adsorbed and hydrogen-bonded acid. TPD curves attributed to the ketonization products: molecular ion of $\mathrm{CO}_{2}$ with $\mathrm{m} / \mathrm{z}=44$, and molecular ion of 3-pentanone with $\mathrm{m} / \mathrm{z}=86$ and its fragment ions with $\mathrm{m} / \mathrm{z}=72,57,29$. TPD curve attributed to water desorption: fragment ion of molecular ion of water with $m / z=17$. (C) Vapor pressure measured as a function of temperature $\left(\mathrm{P} / \mathrm{T}\right.$ curve); deconvolution of $\mathrm{P} / \mathrm{T}$ curve $\left(\mathrm{R}^{2}=0.99554\right)$; experimental data is black line, fitting curve-Red line, Gaussians-Green line. 
Table 1. Kinetic parameters (temperature of the maximum desorption rate $T_{m a x}$, reaction order $n$, activation energy $E^{\neq}$, pre-exponential factor $v_{0}$ and activation entropy $\left.d S^{\neq}\right)$of ketonization of reaction series of carboxylic acids on the $1 \mathrm{CeSi}$ surface $(0.6 \mathrm{mmol} / \mathrm{g})$. Sum of the Taft Induction Constants ( $\left.\sum \sigma^{*}\right)$ and Sum of the Taft Steric Constants $\left(\sum E_{s}\right)$ of the Substituents at the Reaction Center.

\begin{tabular}{|c|c|c|c|c|c|c|c|c|c|c|c|}
\hline Acid & $\Sigma E_{S}$ & $\Sigma \sigma^{*}$ & $T_{\max },{ }^{\circ} \mathrm{C}$ & $m / z$ & $n$ & $\begin{array}{c}E^{\neq}, \\
\mathrm{kJ} \cdot \mathrm{mol}^{-1}\end{array}$ & $\begin{array}{c}v_{0}, \mathrm{~s}^{-1},(\mathrm{n}=1) \\
\mathrm{mol}^{-1} \mathrm{~s}^{-1},(\mathrm{n}=2)\end{array}$ & $\begin{array}{c}d S^{\neq}, \mathrm{cal}^{-\mathrm{K}^{-1}} \\
\mathrm{~mol}^{-1}\end{array}$ & $D \pm \%$ & $R^{2 \mathrm{a}}$ & $\begin{array}{c}E^{\neq \mathrm{b}} \\
\mathrm{kJ} \cdot \mathrm{mol}^{-1}\end{array}$ \\
\hline \multirow[b]{2}{*}{ Acetic C2 } & \multirow{2}{*}{3.72} & \multirow{2}{*}{1.2} & \multirow[b]{2}{*}{247} & \multirow{2}{*}{58} & 1 & 119 & $5.3 \times 10^{9}$ & -15 & 2.5 & 0.982 & 115.1 \\
\hline & & & & & 2 & 212 & $3.5 \times 10^{19}$ & 30 & 11 & 0.957 & - \\
\hline \multirow{2}{*}{ Propionic C3 } & \multirow{2}{*}{2.48} & \multirow{2}{*}{0.8} & \multirow[b]{2}{*}{266} & \multirow[b]{2}{*}{86} & 1 & 122 & $4.4 \times 10^{9}$ & -16 & 4 & 0.970 & 119.4 \\
\hline & & & & & 2 & 271 & $6.7 \times 10^{24}$ & 54 & 43 & 0.879 & - \\
\hline \multirow{2}{*}{ Butyric C4 } & \multirow{2}{*}{2.41} & \multirow{2}{*}{0.7} & \multirow{2}{*}{262} & \multirow{2}{*}{114} & 1 & 113 & $2.4 \times 10^{9}$ & -17 & 3.4 & 0.972 & 118.5 \\
\hline & & & & & 2 & 252 & $9.7 \times 10^{22}$ & 45 & 21 & 0.922 & - \\
\hline \multirow{2}{*}{ Isobutyric C4 } & \multirow{2}{*}{1.24} & \multirow[b]{2}{*}{0.4} & \multirow[b]{2}{*}{284} & \multirow[b]{2}{*}{114} & 1 & 128 & $7.4 \times 10^{9}$ & -15 & 0.4 & 0.995 & 123.6 \\
\hline & & & & & 2 & 241 & $8.7 \times 10^{20}$ & 36 & 6 & 0.962 & - \\
\hline \multirow{2}{*}{ Valeric C5 } & \multirow{2}{*}{2.12} & \multirow{2}{*}{0.685} & \multirow{2}{*}{268} & \multirow{2}{*}{142} & 1 & 123 & $4.8 \times 10^{9}$ & -15 & 2.5 & 0.964 & 119.9 \\
\hline & & & & & 2 & 254 & $5.2 \times 10^{22}$ & 44 & 10 & 0.930 & - \\
\hline \multirow{2}{*}{ Pivalic C5 } & \multirow[b]{2}{*}{0} & \multirow[b]{2}{*}{0} & \multirow[b]{2}{*}{290} & \multirow{2}{*}{$57^{c}$} & 1 & 130 & $5.2 \times 10^{8}$ & -20 & 4.8 & 0.962 & - \\
\hline & & & & & 2 & 251 & $4.2 \times 10^{19}$ & 30 & 40 & 0.853 & - \\
\hline \multirow{2}{*}{ Hexanoic C6 } & \multirow{2}{*}{2.09} & & & & 1 & 120 & $1.3 \times 10^{9}$ & -18 & 4.7 & 0.958 & 120.1 \\
\hline & & 0.67 & 269 & 85 & 2 & 205 & $1.0 \times 10^{17}$ & 18 & 13 & 0.933 & - \\
\hline & & & & & 1 & 122 & $1.6 \times 10^{9}$ & -18 & 6 & 0.947 & 120.8 \\
\hline Heptanoic C7 & 2.08 & 0.55 & 272 & 142 & 2 & 282 & $1.7 \times 10^{25}$ & 56 & 20 & 0.920 & - \\
\hline & & & & & 1 & 122 & $1.4 \times 10^{9}$ & -18 & 9.0 & 0.940 & 123.1 \\
\hline Octanoic C8 & - & 0.49 & 282 & 85 & 2 & 250 & $5.3 \times 10^{21}$ & 40 & 32 & 0.900 & - \\
\hline & & & & & 1 & 119 & $1.5 \times 10^{9}$ & -18 & 4.9 & 0.966 & 124.9 \\
\hline Nonanoic C9 & - & 0.43 & 290 & 85 & 2 & 209 & $2.0 \times 10^{17}$ & 18 & 14 & 0.944 & - \\
\hline & - & & & & 1 & 124 & $5.2 \times 10^{9}$ & -15 & 3.5 & 0.960 & 125.4 \\
\hline Decanoic C10 & - & 0.45 & 292 & 72 & 2 & 295 & $5.2 \times 10^{26}$ & 62 & 21 & 0.903 & - \\
\hline
\end{tabular}

${ }^{\mathrm{a}}$ The coefficient of determination. ${ }^{\mathrm{b}} E^{\neq}=\ln (B / \ln B) R T_{\max }{ }^{\mathrm{c}}$ The fragment ion of 2-dimethyl-4-methyl-3-pentanone. 
The possible side products were monitored but were not definitively detected, including pathways b, c, d, e, Scheme 3. The complex shape of the TPD curve for the ion with $\mathrm{m} / \mathrm{z}=44$ may be evidence of the presence of path $(\mathrm{f})$ at $\sim 200^{\circ} \mathrm{C}$. Our assumption confirms the presence of peaks in the TPD curves at $\sim 200{ }^{\circ} \mathrm{C}$ for ions with $\mathrm{m} / \mathrm{z}=28$ and 29 , which are the most intense in the ethane EI mass-spectrum [62]. The $\mathrm{P} / \mathrm{T}$ curve was decomposed into individual Gaussians in order to semi-quantify the contribution of ketonization and decarboxylation with the formation of ethane in the process of propionic acid conversion, Figure 1C.

A comparative analysis of the peaks on the TPD curves (Figure 1B) with the peaks on the P/T curve (Figure 1C) shows that the $\mathrm{P} / \mathrm{T}$ curve is the result of a superposition of several peaks that correspond to the desorption of water, physically adsorbed and hydrogen-bonded propionic acid, and desorption of pyrolysis products. The decomposition of the P/T curve into individual Gaussians allowed us to identify peaks 1 and 3 with desorption of propionic acid in molecular form, peaks 2 and 6 with processes of desorption of water and peaks 4 and 5 with desorption of products of catalytic transformations, because they are centered at the same temperature as corresponding TPD peaks, Table 2, Figure 1B,C.

The calculated integral intensities of peaks $1,3,4$, and 5 make it possible to semi-quantify the efficiency of the catalytic conversion of propionic acid, Table 2. The degree of conversion of propionic acid during the pyrolysis is about 0.67 , while the selectivity for the formation of 3-pentanone is above 0.90 and ethane is about 0.02 . The obtained data are in good agreement with previously published data $[63,64]$ regarding the catalytic activity of catalytic systems based on $\mathrm{CeO}_{2} / \mathrm{SiO}_{2}$ and catalytic systems based on $\mathrm{ZrO}_{2}$ in the ketonization of propionic acid [37]. The selectivity of 3-pentanone is higher than $97.5 \%$ on the $\mathrm{ZrO}_{2}$-based catalysts [37] and $>93 \%$ on the $\mathrm{CeO}_{2} / \mathrm{SiO}_{2}$-based catalysts [63]. Deng et al. [64] have also confirmed a high catalytic activity of $\mathrm{CeO}_{2} / \mathrm{SiO}_{2}$ for acetic acid ketonization because it could convert acetic acid to acetone with high selectivity $96.63 \%$. The activation energy $\mathrm{E}^{\neq}$ for propionic acid ketonization with 3-pentanone formation is $122 \mathrm{~kJ} \cdot \mathrm{mol}^{-1}$ (calculated by Arrhenius plot method), and $119 \mathrm{~kJ} \cdot \mathrm{mol}^{-1}$ (calculated by the modified equation), Table 1 . These data also are in good agreement with the previous reports of $117 \mathrm{~kJ} \cdot \mathrm{mol}^{-1}$ on $\mathrm{m}-\mathrm{ZrO}_{2}$ [33] and $124 \mathrm{~kJ} \cdot \mathrm{mol}^{-1}$ on $\mathrm{m}-\mathrm{ZrO}_{2}$ and $100 \mathrm{~kJ} \cdot \mathrm{mol}^{-1}$ on $\mathrm{t}-\mathrm{ZrO}_{2}[37]$.

Conversion and selectivity are highly dependent on reaction conditions, especially temperature. The effect of the reaction temperature on the degree of conversion and selectivity to ketone was studied $[16,37,64]$. It was shown that an increase in temperature to $425^{\circ} \mathrm{C}$ allows the conversion of acetic acid to be achieved at about $93 \%-100 \%[16,64]$. Importantly, the highest conversion of propionic acid on the zirconium surface was observed at a temperature of the highest ketonization rate [37]. Therefore, we can assume that the obtained temperature values of $\mathrm{T}_{\max }$ (Table 1), which are attributed to the temperature of the maximum rate of ketonization reaction of $\mathrm{C}_{n} \mathrm{H}_{2 n+1} \mathrm{COOH}(n=1-9)$, can be very useful for choosing the optimal conditions for the catalytic conversion of carboxylic acids into symmetric ketones. $\mathrm{T}_{\max }$ for the investigated series of carboxylic acids is in the range $247-292{ }^{\circ} \mathrm{C}$. We suggest that optimal temperature conditions for the efficient catalytic ketonization of carboxylic acids over $\mathrm{CeO}_{2} / \mathrm{SiO}_{2}$ catalyst could also be in this range.

It is known that cerium-based oxides are effective catalysts of ketonization [21,38,56,63,64]. Therefore catalytic systems for industrial applications have been developed on their basis. Gliński et al. [63] investigated over 20 metal oxides supported on $\mathrm{SiO}_{2}, \mathrm{Al}_{2} \mathrm{O}_{3}$, and $\mathrm{TiO}_{2}$. It was demonstrated, that $\mathrm{CeO}_{2}$ was proved to be the most efficient as an active phase for ketonization reaction [63,64]. Gliński and coworkers [63] have suggested that high activity of $\mathrm{CeO}_{2}$ supported on $\mathrm{SiO}_{2}, \mathrm{TiO}_{2}$, and $\mathrm{Al}_{2} \mathrm{O}_{3}$ are a result of the synergy due to the interaction between the $\mathrm{CeO}_{2}$ and oxide support. We also assume synergies between the support and the active phase of the catalyst that contains strong basic centers. This determines the high catalytic activity of $\mathrm{CeO}_{2}$ materials. 
Table 2. The calculated integral intensities for the peaks obtained by deconvolution of the $P / T$ curve $\left(R^{2}=0.99554\right.$, Figure $\left.1 C\right)$.

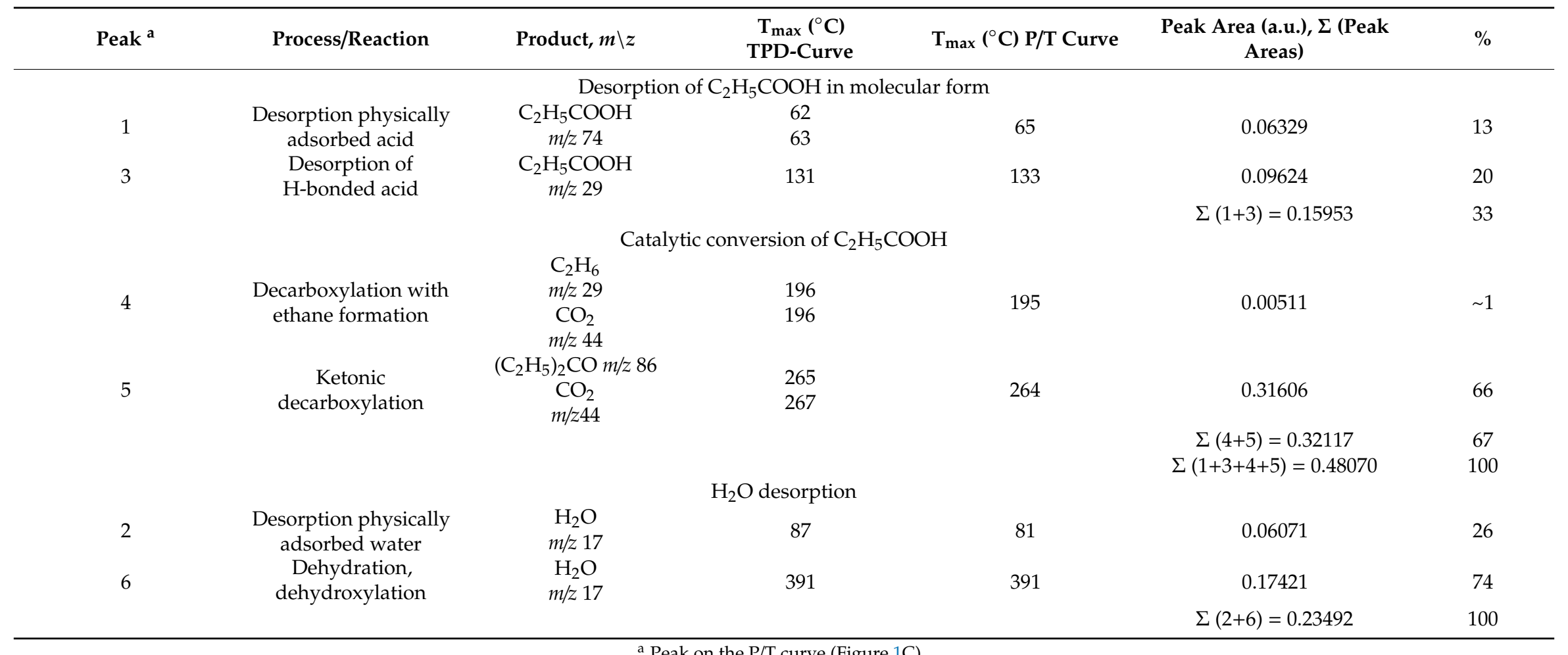

${ }^{a}$ Peak on the $\mathrm{P} / \mathrm{T}$ curve (Figure 1C). 


\subsection{Analysis of Kinetics Data}

Detailed and targeted kinetic studies for reaction series of aliphatic carboxylic acids C2-C10 (acetic, propionic, butyric, isobutyric, valeric, pivalic, hexanoic, heptanoic, nonanoic, octanoic, decanoic) on the surface of nanosized $\mathrm{CeO}_{2} / \mathrm{SiO}_{2}$ have been investigated by temperature-programmed desorption mass spectrometry (TPD MS), Table 1. The obtained data and our previous study [41] showed that $\mathrm{CeO}_{2} / \mathrm{SiO}_{2}$ is suitable catalysts for ketonization.

The kinetic parameters $\left(n, T_{\max }, E^{\neq}, v_{0}, d S^{\ddagger}\right)$ of the reaction of ketone formation were calculated, as described previously [43] (Table 1). The obtained values of the kinetic parameters show that the reaction proceeds according to the first order, since the determination coefficients $\left(R^{2}\right)$ are much higher, and the calculated deviation values are much smaller for the first order than for the second order. In addition, the first order of the reaction was also confirmed by us earlier [41] by studying the influence of the degree of surface coverage on the reaction rate. Namely, the absence of $T_{\max }$ displacement towards low temperatures with increasing acid concentration on the surface indicates the first order [65].

The pre-exponential factor for this reaction series has close values within the limits of the same order. This indicates that the transition state for this reaction series has a similar structure. Thus, the entropy of activation for this series is constant $\left(d S^{\neq}=c o n s t\right)$, so this reaction series is an isentropic series. This fact has allowed us to apply a Redhead peak maximum method to calculate the activation energy [66]. This method avoids the effect of various distortions in the form of a peak on the calculated values of the activation energy that can be produced by using complete analysis of TPD curves and the Arrhenius plot method [65-68]. In this work, we used the modified Equation (1) as suggested by Kislyuk and Rozanov on the basis of Redhead equation [67]. This relation directly includes the temperature of the peak maximum $\mathrm{T}_{\max }$ [67]:

$$
E^{\ddagger}=R T_{\max } \ln (B / \ln B)
$$

where

$$
B=\left(n v_{0} T_{\max } C_{\max }{ }^{n-1}\right) b
$$

In this formula, $n$ is the reaction order, $v_{0}$ is the pre-exponential factor, $C^{n-1}$ max is the concentration of the adsorbate at $T_{\max }$ and $b$ is the value of the sample heating rate.

A study of a number of acids shows an increase in the $\mathrm{T}_{\max }$ of reaction with an increase in the number of the methylene units and the branching in the molecule (Table 1). The corresponding increase in the activation energy was also obtained by using modified Equation (1) and the arithmetic average of the pre-exponential factor $v_{0 \text { average }}=1 / 10 \Sigma v_{0}$ acid $=3.53 \pm 1.89 \times 10^{9} \mathrm{~s}^{-1}$ for the reaction series of 10 acids.

Thus, as a result of the kinetic analysis carried out, it is established that the reaction is of first order, the activation entropy has a negative value, i.e., the number of degrees of freedom in the transition state decreases and the transition state has a highly ordered structure. Thus, the next task is to establish how changes in the structure of the acid molecule affect the activation energy. This task can be solved by investigating the effect of the substituent using the approaches of LFERs.

\subsection{Analysis of Substituent Effects (Taft Plots) or Linear Free Energy Relationships (LFERs)}

We were unable to find literature data on the use of LFERs to study the mechanism of ketonization, despite the fact that more in-depth data about the structure of the transition state can be obtained from studies of substituent effects [42]. So the next step was to search for correlations between the kinetic parameters and the thermodynamic ones: the activation energy and the Taft's constants of substituents, respectively. An important step in the search for such correlations is the $E^{\neq}-\sigma^{*}$ and $E^{\ddagger}$-Es analysis, which allows us to determine the reaction center in the molecule. Such correlations can be obtained only if the reaction center is chosen correctly. Taft's correlation was obtained (Figure 2A) only if the $\alpha$-carbon atom was chosen as the reaction center, and not, for example, the $\beta$-carbon atom or 
the carbon atom of the carboxyl group. So, a linear correlation between the activation energies and the sum of the Taft steric constants at the $\alpha$-carbon atom $\left(E^{\neq}-\Sigma E s\right)$ with a high squared correlation coefficient $R^{2}=0.9488$ indicates that the ketonization reaction is sterically sensitive, Figure $2 \mathrm{~A}$. The correlation $\mathrm{E}^{\neq}-\Sigma \sigma^{*}$ sum of induction Taft's constants (Figure $2 \mathrm{~B}$ ) has a low value of the squared correlation coefficient $R^{2}=0.8227$. These data indicate that the activation energy of ketonization is predominantly dependent on the steric effects of the substituents. That is, the transition state is less sensitive to the inductive effect of the substituents, although it is possible that electron-donor substituents slow down this reaction. The Taft correlation $E^{\neq}-\Sigma E s$ indicates that the LFER principle is applicable to this reaction series. The presence of large substituents in the reaction center may prevent the interaction of atoms and thereby slow down the reaction or make it impossible. The steric effect does not allow to achieve the necessary conformation in the transition state for the realization of ketonization, the so-called "tert-butyl effect". Although pivalic acid does not form a pivalon, it is an important member of this reaction series. Pivalic acid is the standard for this reaction series since the sum of both the induction and steric Taft's constants for the $\alpha$-carbon atom of the pivalic acid is $0\left(\left(\Sigma \mathrm{Es}=3 \times \mathrm{Es}\left(\mathrm{CH}_{3}\right)=3 \times 0=0 ; \Sigma \sigma^{*}=3 \times \sigma^{*}\left(\mathrm{CH}_{3}\right)=3 \times 0=0\right)\right.$. Thus, the greatest steric effect should be observed, namely, for pivalic acid.

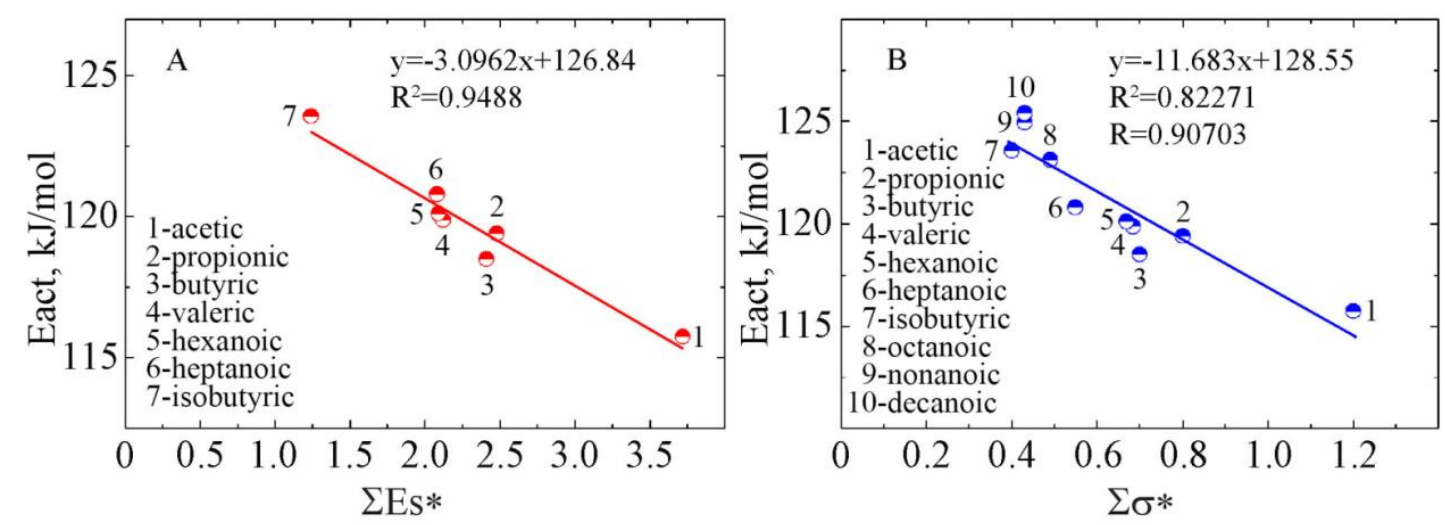

Figure 2. (A) Linear correlation between the activation energies of ketonization of reaction series of carboxylic acids (C2-C10) on $1 \mathrm{CeSi}$ and the sum of the Taft steric constants $\left(\Sigma E s^{*}\right)$ at the $\alpha$-carbon atom of carboxylic acids. (B) The correlation between the activation energies and the sum of the Taft induction constants $\left(\Sigma \sigma^{*}\right)$ at the $\alpha$-carbon atom of the carboxylic acids.

\subsection{Study of DKIE During Catalytic Ketonization of CD3COOH (D3)}

The isotopic effect is one of the most powerful tools for establishing the mechanism of reactions along with LFER and kinetic studies [42]. The presence of a primary H/D isotopic effect indicates that the bond containing the $\mathrm{H}$ atom being broken or formed in a kinetically relevant step [42]. However, there are contradictory data in the literature. Thus, for example, Hendren and coworkers [27] obtained the values of the primary isotopic effects $k(H)=k(D)$ between 1.4 and 6.7 for the ketonization reaction. The absence of a primary isotopic effect was demonstrated in the study of the ketonization of deuterated acetic acid [26]. A very low value of the primary isotopic effect $k(H) / k(D)=1.1$ was obtained in the work of Wang and Iglesia [36]. Thus, recent experimental data of the DKIE [26,36], as well as quantum chemical calculations $[32,33]$ completely exclude enolization as a rate-limiting stage. However, this is not enough to completely exclude it as a necessary stage. In this regard, TPD-MS was used to an elucidation of DKIE by studying of the kinetics of the thermal transformations of deuterated acetic acid $\left(\mathrm{CD}_{3} \mathrm{COOH}\right)$ on the surface of the nanocomposites $\mathrm{CeO}_{2} / \mathrm{SiO}_{2}$ with higher amount of $\mathrm{CeO}_{2}(\mathrm{hCeSi})$.

\subsubsection{The Distribution of Acetone Isotopomers}

The results of the TPD-MS studies confirm the presence of isotopic exchange on the surface of the catalysts, (Figure 3A,B). The peaks on the TPD curves corresponding to the isotopomers of acetone have 
a different intensity, and different $\mathrm{T}_{\max }$ localization, (Figure 3A,B). Earlier, in 1978, Munuera et al. [29], in their extremely important work, had already estimated the relative yield of isotopomers of acetone as result of the ketonization of a mixture of acids $\mathrm{CD}_{3} \mathrm{COOH}(76 \%)$ and $\mathrm{CH}_{3} \mathrm{COOH}(24 \%)$ adsorbed on the surface of titanium dioxide. However, due to the then instrumental imperfection, these estimates were not accurate enough, since they were made only on the basis of the peak height in the mass spectra at a fixed temperature $\sim 250^{\circ} \mathrm{C}$. It is necessary to take into account the integrated intensity of the peaks for correct estimation.
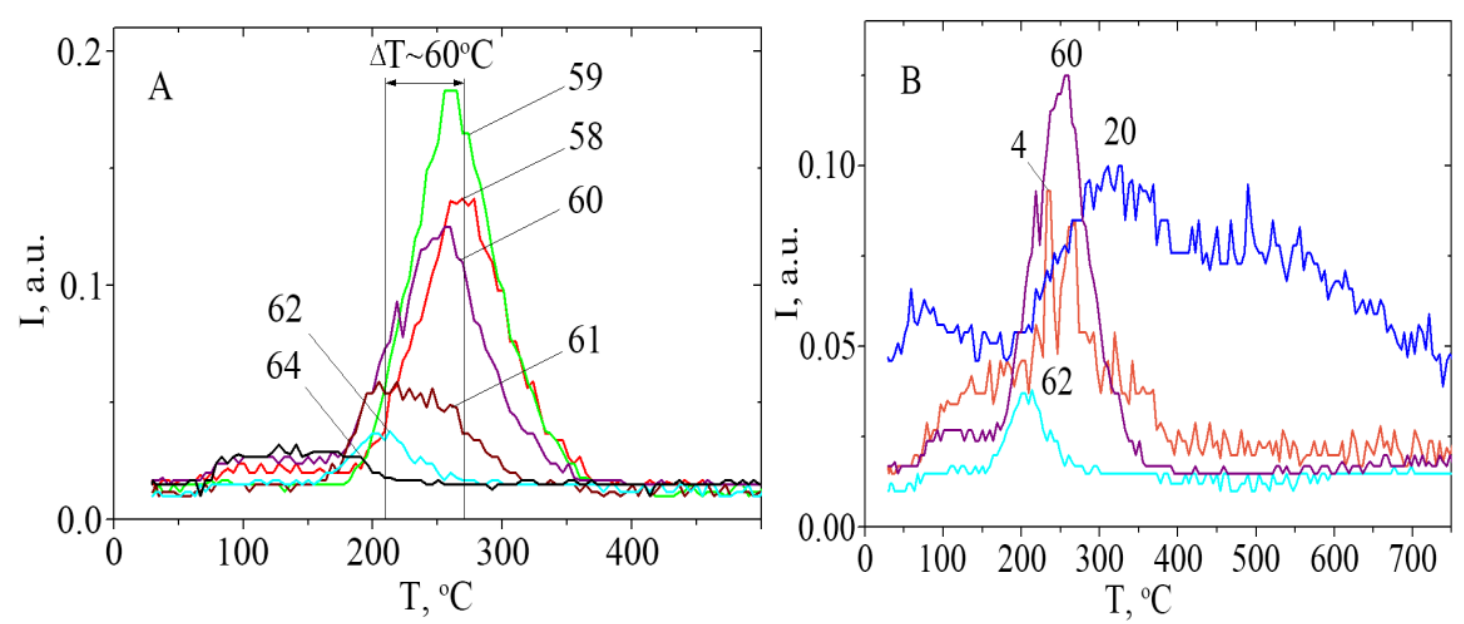

Figure 3. (A) TPD curves for the ions of acetone isotopomers with $m / z=64,62,61,60,59$, 58; (B) TPD curves for the ions of acetone isotopomers with $m / z=62,60$; TPD curves for the ions of $\mathrm{D}_{2} \mathrm{O}^{+}$with $m / z=20$ for the ions of $\mathrm{D}_{2}{ }^{+}$with $\mathrm{m} / z=4$ were obtained during the pyrolysis of $\mathrm{CD}_{3} \mathrm{COOH}$ on the hCeSi surface.

In this regard, the mathematical procedure has been conducted to obtain the correct values of $T_{\max }$ and integral intensities of the isotopomers peaks (see Figure 4, Figures S1-S5 and Table 3). Thus, the integral intensities of TPD peaks and distribution (\%) for ions of acetone isotopomers with $\mathrm{m} / \mathrm{z}=62$ $(4 \%), 61(11 \%), 60(24 \%), 59(35 \%), 58(26 \%)$ were obtained during the pyrolysis of isotopic-labeled acetic acid $\mathrm{CD}_{3} \mathrm{COOH}$ on the hCeSi surface (Figure 4 and Table 3). It is noteworthy that the sum of the integral intensities of TPD peaks of ions of isotopomers with $\mathrm{m} / \mathrm{z}=62,61,60,59,58$ is very close to integral intensities of TPD peaks of molecular ions of $\left(\mathrm{CH}_{3}\right)_{2} \mathrm{CO}$ and $\left(\mathrm{CH}_{3}\right)_{2}{ }^{13} \mathrm{CO}$ that were obtained during the pyrolysis of nonlabeled acetic acid and ${ }^{13} \mathrm{C}$-labeled acetic acid (Figure 5, Figures S6 and S7, and Table 3). 


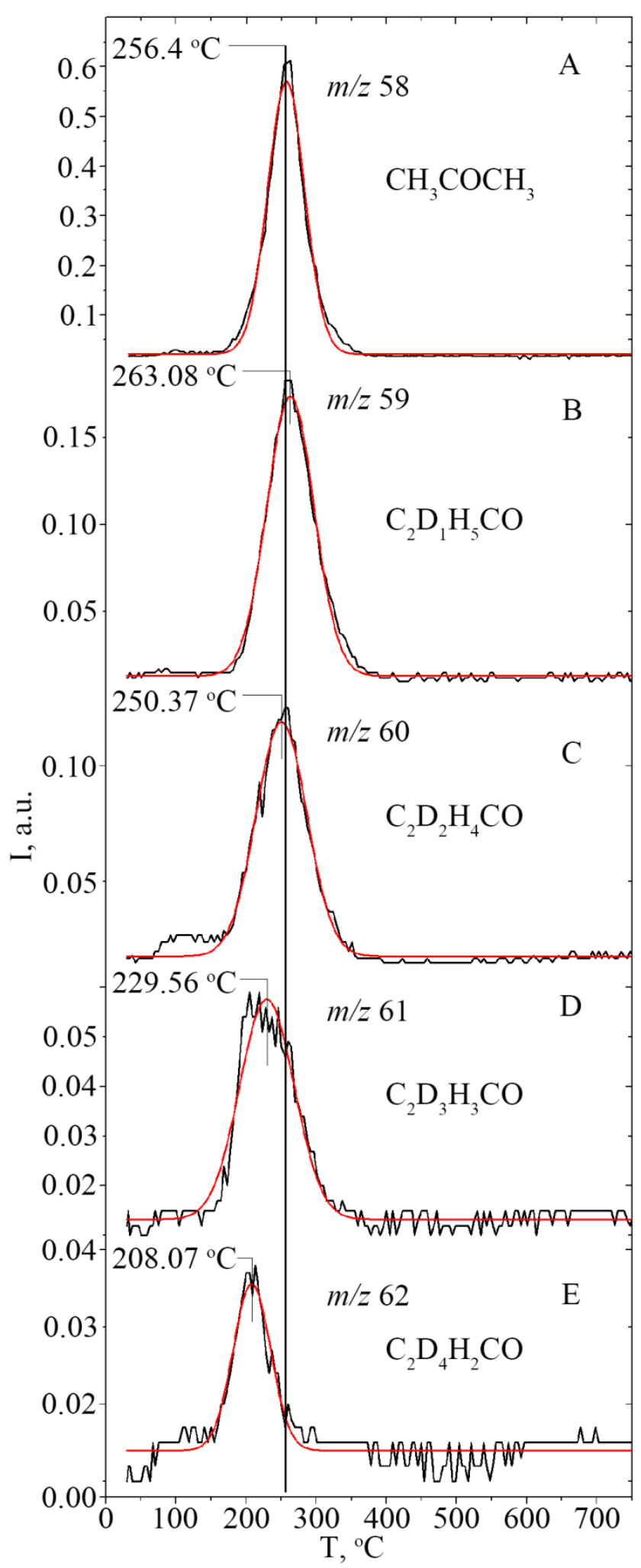

Figure 4. Deconvolution of TPD curve for the ion of acetone with $\mathrm{m} / \mathrm{z}=58$ that was obtained during the pyrolysis of nonlabeled acetic acid on the hCeSi surface (A). Deconvolution of TPD-curves for the ions of acetone isotopomers with $\mathrm{m} / \mathrm{z}=62,61,60$ and 59 that were obtained during the pyrolysis of deuterated acetic acid on the hCeSi surface (B-E). Experimental data is the black line; the fitting curve is the red line. 
Table 3. Temperature of the maximum desorption rate $T_{\max }$, integral intensity $\left(\int \mathrm{I}(\mathrm{m} / \mathrm{z})\right)$ and distribution (\%) of acetone isotopomers with $m / z=64,62,61,60,59$, 58 obtained during the catalytic pyrolysis of isotopic-labeled acetic acid $\mathrm{CD}_{3} \mathrm{COOH}, \mathrm{CH}_{3}{ }^{13} \mathrm{COOH}$ and nonlabeled acetic acid $\mathrm{CH}_{3} \mathrm{COOH}$ on the hCeSi surface $\left(0.6 \mathrm{mmol} \cdot \mathrm{g}^{-1}\right)$.

\begin{tabular}{|c|c|c|c|c|}
\hline $\begin{array}{c}\mathrm{m} / \mathrm{z} \\
\text { Isotopomer of Acetone }\end{array}$ & $\mathbf{T}_{\max }$ & $\int \mathrm{I}(m / z)$, a.u. & Distr., \% & $R^{2} \mathbf{a}$ \\
\hline \multicolumn{5}{|c|}{$\mathrm{CD}_{3} \mathrm{COOH}$} \\
\hline $58, \mathrm{C}_{2} \mathrm{D}_{0} \mathrm{H}_{6} \mathrm{CO}$ & 269.9 & 10.21 & 26.20 & 0.9906 \\
\hline $59, \mathrm{C}_{2} \mathrm{D}_{1} \mathrm{H}_{5} \mathrm{CO}$ & 263.1 & 13.58 & 34.85 & 0.9929 \\
\hline $60, \mathrm{C}_{2} \mathrm{D}_{2} \mathrm{H}_{4} \mathrm{CO}$ & 250.4 & 9.17 & 23.53 & 0.9817 \\
\hline $61, \mathrm{C}_{2} \mathrm{D}_{3} \mathrm{H}_{3} \mathrm{CO}$ & 229.5 & 4.32 & 11.09 & 0.9774 \\
\hline $62, \mathrm{C}_{2} \mathrm{D}_{4} \mathrm{H}_{2} \mathrm{CO}$ & 208.1 & 1.44 & 3.70 & 0.9641 \\
\hline $64, \mathrm{C}_{2} \mathrm{D}_{6} \mathrm{H}_{0} \mathrm{CO}$ & - & $<0.25$ & $<0.64$ & - \\
\hline$\sum \int \mathrm{I}(\mathrm{m} / \mathrm{z})$ & & $\sim 38.97$ & $\sim 100$ & - \\
\hline \multicolumn{5}{|c|}{$\mathrm{CH}_{3}{ }^{13} \mathrm{COOH}$} \\
\hline$\left(\mathrm{CH}_{3}\right)_{2}{ }^{13} \mathrm{CO}$ & 255.7 & $\sim 37.30$ & $\sim 100$ & 0.9955 \\
\hline \multicolumn{5}{|c|}{$\mathrm{CH}_{3} \mathrm{COOH}$} \\
\hline$\left(\mathrm{CH}_{3}\right)_{2} \mathrm{CO}$ & 256.4 & $\sim 36.79$ & $\sim 100$ & 0.9912 \\
\hline
\end{tabular}

${ }^{a}$ The coefficient of determination.
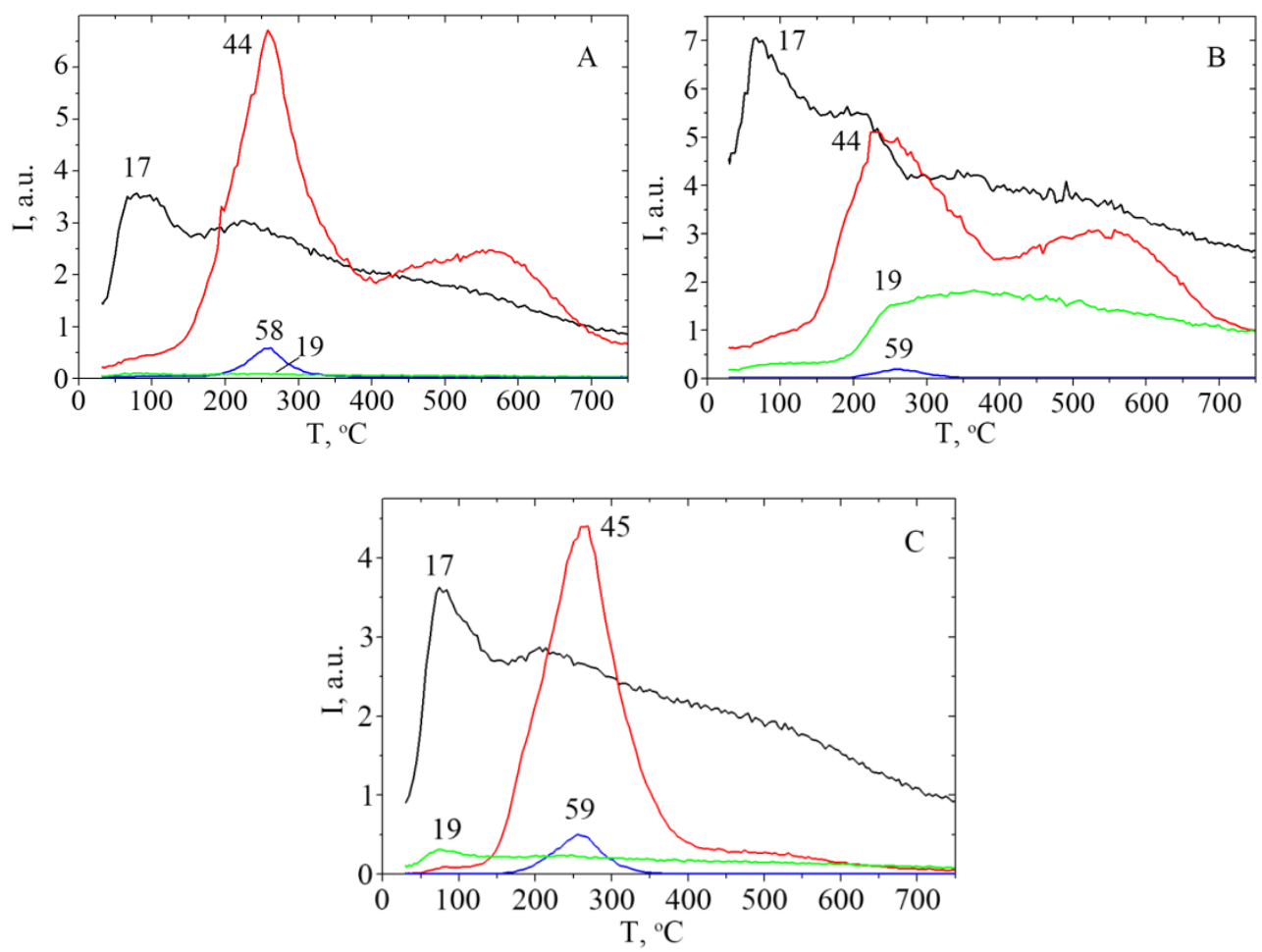

Figure 5. TPD curves for the molecular ion of acetone with $\mathrm{m} / z=58$, molecular ion of ${ }^{13} \mathrm{C}$-labeled acetone with $\mathrm{m} / z=59$, molecular ion of $\mathrm{CO}_{2}$ with $\mathrm{m} / z=44$, molecular ion of ${ }^{13} \mathrm{CO}_{2}$ with $\mathrm{m} / \mathrm{z}=45$, ion of $\mathrm{H}_{3} \mathrm{O}^{+}$with $m / z=19$, fragment ion of deuterated water $\mathrm{HDO}$ with $m / z=19$ and fragment ion of water with $m / z=17$ were obtained during the pyrolysis of $\mathrm{CH}_{3} \mathrm{COOH}(\mathbf{A}) ; \mathrm{CD}_{3} \mathrm{COOH}(\mathbf{B}) ; \mathrm{CH}_{3}{ }^{13} \mathrm{COOH}(\mathbf{C})$ on the hCeSi surface.

The maximum yield is observed for monodeuterated acetone with $m / z=59$, (Figures 3A, 4B and $5 \mathrm{~A})$. The increase in the number of deuterium atoms decreases the yield of the isotopomer. Unfortunately, we were unable to estimate the amount of fully deuterated $\left(m / z=64, \mathrm{C}_{2} \mathrm{D}_{6} \mathrm{H}_{0} \mathrm{CO}\right)$ and mono-deuterated acetone $\left(m / z=63, \mathrm{C}_{2} \mathrm{D}_{5} \mathrm{H}_{1} \mathrm{CO}\right)$ because their molecular weights are equal to the 
molecular weights of the molecular ions $\mathrm{CD}_{3} \mathrm{CO}_{2} \mathrm{D}$ and $\mathrm{CD}_{3} \mathrm{CO}_{2} \mathrm{H}$, respectively. As a consequence, overlapping of the peaks of these isotopomers of acetone $\left(\mathrm{C}_{2} \mathrm{D}_{6} \mathrm{H}_{0} \mathrm{CO}\right.$ and $\left.\mathrm{C}_{2} \mathrm{D}_{5} \mathrm{H}_{1} \mathrm{CO}\right)$ with desorption peaks of physically adsorbed $\mathrm{CD}_{3} \mathrm{CO}_{2} \mathrm{D}$ and $\mathrm{CD}_{3} \mathrm{CO}_{2} \mathrm{H}$ acid molecules could occur.

It is most likely that the $\mathrm{H} / \mathrm{D}$ isotope exchange on the surface and the ketonization reaction are two independent processes that are not related to each other. It seems that isotopic exchange easily proceeds on the oxide surface at temperatures much lower than a temperature at the start of ketonization. The adsorption layer of isotopomers of surface acetates $-\mathrm{O}-\mathrm{C}(=\mathrm{O})-\mathrm{CD}_{\mathrm{n}} \mathrm{H}_{3-\mathrm{n}}$ with a different percentage distribution is formed in the isotopic exchange result, which is due to the efficiency of H/D exchange on the surface of a particular oxide. The efficiency of $\mathrm{H} / \mathrm{D}$ exchange depends on the nature of the oxide surface. Based on the experimental data obtained, it can be said that on the surface of $\mathrm{CeO}_{2} / \mathrm{SiO}_{2}$, the H/D exchange starts at a quite low temperature $\leq 150{ }^{\circ} \mathrm{C}$ (Figure $3 \mathrm{~A}, \mathrm{~B}$ ). This process can likely proceed very easy through the tunneling mechanism, or through an enolization (see Scheme 2). H/D exchange was observed by Kozhevnikov et al. as a result of the exchange between surface acetates and the Brønsted acid sites [39].

Upon further heating, these exchanged deuterium atoms are desorbed in the form of deuterated water molecules DHO $(m / z=19)$ and $\mathrm{D}_{2} \mathrm{O}(\mathrm{m} / \mathrm{z}=20)$ as a result of dehydration of surface, (Figures 3B and $5 \mathrm{~B})$. The differences in the processes of water desorption during the pyrolysis of isotope-labeled and nonlabeled acetic acids are clearly seen in Figure 5A-C.

\subsubsection{Study of the Magnitude and the Origin of DKIE}

We assume that initially an adsorption layer from the surface complexes of acetic acid isotopomers $\mathrm{D}_{\mathrm{n}} \mathrm{H}_{3-\mathrm{n}} \mathrm{COOH}$ is formed on the surface as a result of the $\mathrm{H}-\mathrm{D}$ exchange. Their percentage distribution is due to the amount and strength of the surface active centers on which the H/D exchange occurs. Furthermore, these surface complexes of acetic acid isotopomers $\mathrm{D}_{\mathrm{n}} \mathrm{H}_{3-\mathrm{n}} \mathrm{COOH}$ are transformed upon heating. As a result of ketonization, seven isotopomers and three isomers of isotope-labeled acetone can be formed: $\mathrm{m} / \mathrm{z}=64,63,62$ ( 2 isomers), 61 ( 2 isomers), 60 ( 2 isomers), 59 and 58 (Scheme 4). The same value of the rate of formation of various isotopomers and accordingly, the same value of the primary DKIE, should be observed if the "beta-ketoacid" mechanism works.

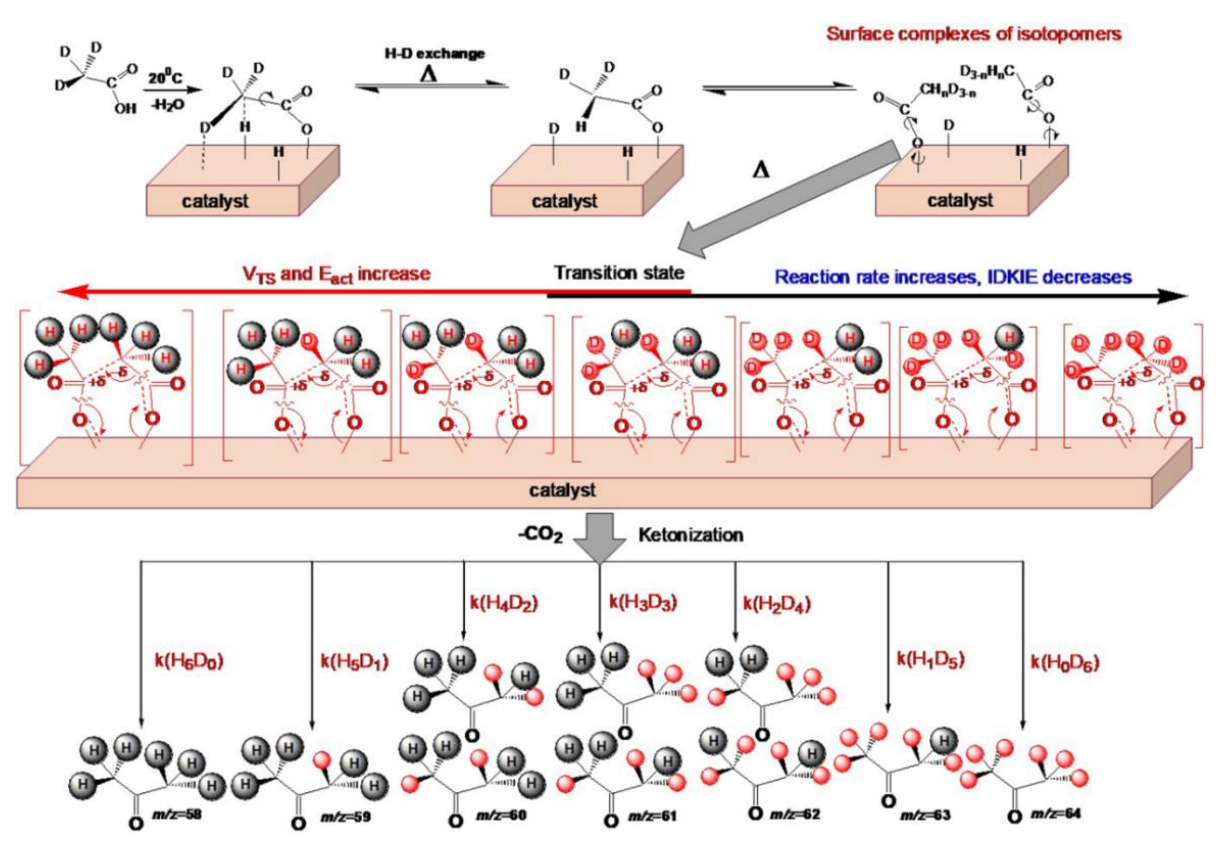

Scheme 4. The possible mechanism of deuterated acetic acid ketonization into the acetone isotopomers involves the simultaneous carbon-carbon bond and carbon dioxide formations in one single step. 
Interestingly, the TPD peaks for the isotopomers of acetone were observed at different temperatures of the maximum desorption rate $\left(T_{\max }\right)$ on the $\mathrm{CeO}_{2} / \mathrm{SiO}_{2}$ surface (see Figures 3 and 4 , Table 3). Most importantly, TPD peaks are shifted to higher temperatures with an increase in the numbers of $\mathrm{H}$-atoms in a molecule of an isotopomer. As was shown earlier in the work performed by Leardini with co-authors, this may indicate the presence of an inverse isotope effect [69]. Determination of the exact value of the isotopic effect is a difficult experimental and calculation problem [42,69]. However, establishing even the type of isotope effect-primary, secondary or inverse-can play a key role in determining the reaction mechanism.

Therefore, we decided to use the modified Taft equation for the DKIE calculation. This equation was earlier proposed in the work of one of the coauthors [43] to study the mechanisms of catalytic reactions using the TPD-MS data:

$$
\operatorname{lgk} / \mathrm{k}_{\mathrm{o}}=\lg (\mathrm{B} / 2.3 \lg \mathrm{B}) \cdot \Delta \mathrm{T}_{\max } / \mathrm{T}_{\mathrm{o} \max }
$$

After some manipulation, we obtain the simple equations for the elucidation of KIE values from TPD-MS data:

$$
\begin{gathered}
\mathrm{KIE}=\mathrm{k} / \mathrm{k}_{\mathrm{o}}=10^{\lg (\mathrm{B} / 2.3 \lg \mathrm{B}) \cdot \Delta \operatorname{Tmax} / \mathrm{To} \max } \\
\mathrm{DKIE}=\mathrm{k}(\mathrm{H}) / \mathrm{k}(\mathrm{D})=10^{\lg (\mathrm{B} / 2.3 \lg \mathrm{B}) \cdot(\operatorname{Tmax}(\mathrm{D})-\operatorname{Tmax}(\mathrm{H})) / \operatorname{Tmax}(\mathrm{D})}
\end{gathered}
$$

The calculating kinetic parameters of ketonization reaction of $\mathrm{CD}_{3} \mathrm{COOH}, \mathrm{CH}_{3} \mathrm{COOH}$ and $\mathrm{CH}_{3}{ }^{13} \mathrm{COOH}$ on the hCeSi surface showed that the pre-exponential factors have close values within the limits of the same order $\sim 10^{9}$ as in the cause of reaction series of carboxylic acids on the 1CeSi surface (Table 4). This result allows using Equation (5) for calculation of DKIE of formation of acetone isotopomers from deuterated acetic acid in comparison with formation acetone from nonlabeled acetic acid.

Table 4. Kinetic parameters (temperature of the maximum desorption rate $T_{\max }$, reaction order $n$, activation energy $E^{\neq}$, pre-exponential factor $v_{0}$ and activation entropy $d S^{\neq}$) of ketonization of $\mathrm{CD}_{3} \mathrm{COOH}, \mathrm{CH}_{3}{ }^{13} \mathrm{COOH}$ and $\mathrm{CH}_{3} \mathrm{COOH}$ on the hCeSi surface; the deuterium kinetic isotope effect $(\mathrm{k}(\mathrm{H}) / \mathrm{k}(\mathrm{D})$ obtained using the suggested Equation (5).

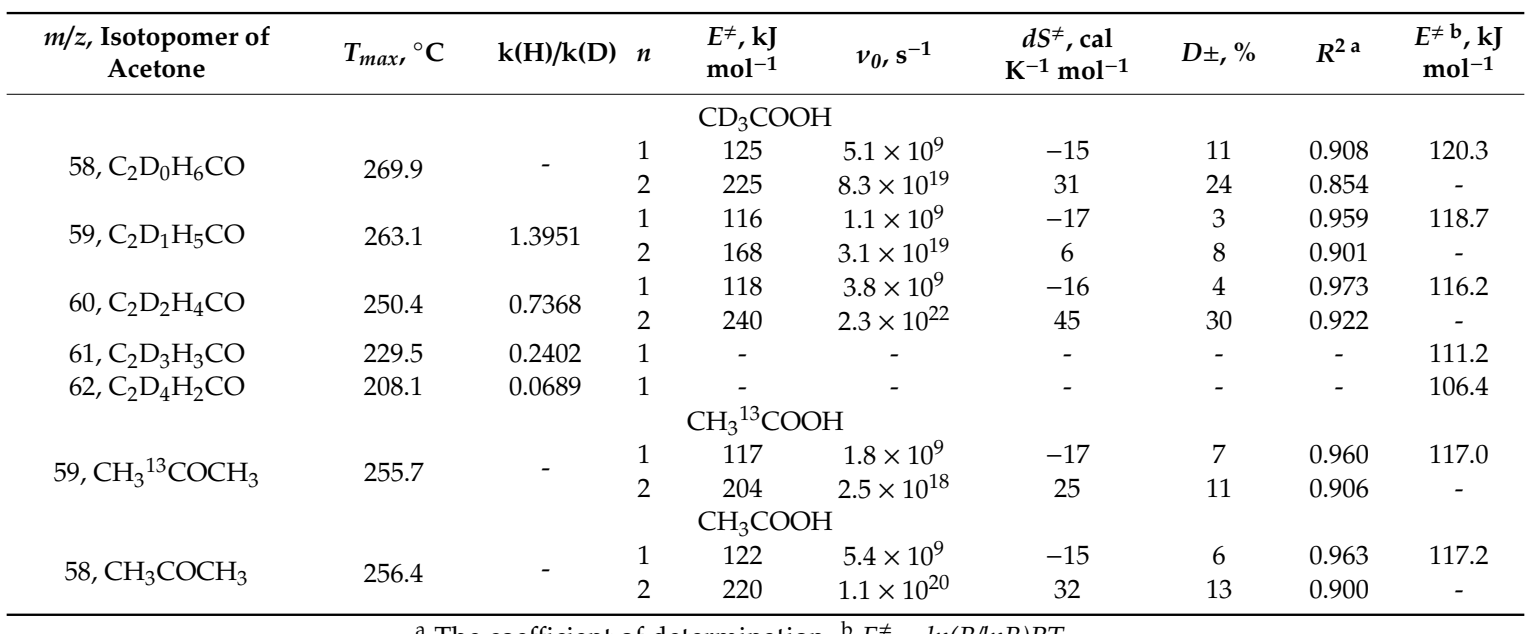

We calculated the isotope effect for isotopomers from one to four deuterium atoms in a molecule (Table 4). The reaction rate constant of formation of the deuterated d4-ketone in 14.5-fold is larger than the reaction rate constant of the formation of nonlabeled ketone from nonlabeled $\mathrm{CH}_{3} \mathrm{COOH}$. In addition, based on the fact that the $T_{\max }$ of acetone formation from $\mathrm{CH}_{3}{ }^{13} \mathrm{COOH}$ is rather close to $T_{\text {max }}$ of acetone formation from $\mathrm{CH}_{3} \mathrm{COOH}$, it can be concluded that $\mathrm{KIE}=\mathrm{k}\left({ }^{12} \mathrm{C}\right) / \mathrm{k}\left({ }^{13} \mathrm{C}\right)$ is about $\sim 1$ (Table 4 and Figure 5). 
The obtained values of inverse DKIE for $\mathrm{C}_{2} \mathrm{D}_{2} \mathrm{H}_{4} \mathrm{CO}(\mathrm{m} / \mathrm{z}=60), \mathrm{C}_{2} \mathrm{D}_{3} \mathrm{H}_{3} \mathrm{CO}(\mathrm{m} / \mathrm{z}=61)$, and $\mathrm{C}_{2} \mathrm{D}_{4} \mathrm{H}_{2} \mathrm{CO}(\mathrm{m} / z=62)$ isotopomers formation confirm the concerted mechanism (Table 4). It is known that inverse DKIE is observed for a mechanism involving concerted bonds reorganization in the cyclic TS-for example, the Cope rearrangement $[42,70,71]$. The reason for this is that the compacting of the cyclic TS is the most important condition and a requirement for this type of reaction. Moreover, the different values of inverse DKIE confirm participating of all deuterium/protium atoms in the cyclic TS. As such, it has been suggested that the concerted mechanism involves the simultaneous single-step formation of a carbon-carbon bond and carbon dioxide release (Scheme 4).

The smaller size of the deuterium atom facilitates the achievement of the planar cyclic TS, in which the synchronous reorganization of bonds can occur easily only due to electron transfer, Scheme 4. Most likely, the reaction is realized in a single surface complex in which two acid residues are monodentate-bonded to two cerium atoms or one cerium atom. Ding and coauthors, by using the in situ Diffuse reflectance infrared Fourier transform spectroscopy (DRIFTS), showed that monodentate carboxylates are much more active then bidentate species during ketonization over $\mathrm{ZrO}_{2}$-based catalysts [37]. It is known that the deuterium atom is $\sim 15 \%$ smaller than the protium atom. Replacement of each next atom of protium by deuterium leads to a decrease in the volume of the TS and, correspondingly, to an increase in the reaction rate and to a decrease in the activation energy. We calculated the activation energies of acetone isotopomers formation by using Equation (1) (Table 4). In point of fact, we can see that an increase in the number of deuterium atoms in the isotopomer molecules lead to a decrease in the activation energy of ketonization. This explains the presence of different isotope effects during the formation of acetone isotopomers.

\section{Materials and Methods}

\subsection{Materials}

The research was carried out for a deuterated acetic acid $\mathrm{D}_{3} \mathrm{CCOOD}$ (Sigma-Aldrich, St.Louis, USA, $>99.5$ atom \%D), ${ }^{13} \mathrm{C}$-labeled acetic acid $\mathrm{H}_{3} \mathrm{C}^{13} \mathrm{COOH}$ (Sigma-Aldrich, St.Louis, USA, 99 atom $\%{ }^{13} \mathrm{C}$ ), and a reaction series of aliphatic carboxylic acids $\mathrm{C}_{\mathrm{n}} \mathrm{H}_{2 \mathrm{n}} \mathrm{COOH}(\mathrm{n}=1-9)$ : acetic (Merck, Schuchardt, Germany, 99.7\%), propionic (Merck, 99.5\%), butyric (Merck, Schuchardt, Germany, 99.5\%), isobutyric (Merck, Schuchardt, Germany, 99.5\%), valeric (Merck, Schuchardt, Germany, 99.5\%), hexanoic (Merck, Schuchardt, Germany, 99.5\%), heptanoic (Merck, Schuchardt, Germany, 99.5\%), octanoic (Merck, Schuchardt, Germany, 99.5\%), nonanoic (Merck, Schuchardt, Germany, 99.5\%), decanoic (Merck, Schuchardt, Germany, 99.5\%), and pivalic (Fluka, 99.5\%). Nonporous nanocomposites $\mathrm{CeO}_{2} / \mathrm{SiO}_{2}$ with low amount of $\mathrm{CeO}_{2}-\mathrm{lCeSi}$ and with higher amount of $\mathrm{CeO}_{2}-\mathrm{hCeSi}$ were prepared by using powdery fumed silica and cerium (III) acetylacetonate (Sigma-Aldrich). The modification of silica with cerium acetylacetonate and the characterization of obtained $\mathrm{CeO}_{2} / \mathrm{SiO}_{2}$ oxides using $\mathrm{X}$-ray diffraction XRD and low-temperature Ar adsorption/desorption were described previously [72] (Table 5).

Table 5. Characteristics of $\mathrm{CeO}_{2} / \mathrm{SiO}_{2}$ catalysts: specific surface area, amount and crystal size of $\mathrm{CeO}_{2}$.

\begin{tabular}{cccc}
\hline Catalysts $^{\mathbf{1}}$ & $\mathbf{S}_{\mathbf{a}}, \mathbf{m}^{\mathbf{2}} \mathbf{g}^{\mathbf{- 1}}$ & Amount of $\mathrm{CeO}_{\mathbf{2}}, \mathbf{\%}$ & $\mathbf{d}_{\mathbf{a v}}, \mathbf{n m}$ \\
\hline $\mathrm{lCeSi}$ & 230 & 12.3 & 5 \\
$\mathrm{hCeSi}$ & 212 & 18.3 & 5 \\
\hline
\end{tabular}

${ }^{1}$ Catalysts preparation and characterization were described previously by Borysenko et al. [72].

Samples of aliphatic carboxylic acids on the surfaces of the nanosized oxides with loadings of $0.6 \mathrm{mmol} \mathrm{g}^{-1}$ were obtained by impregnation. In a typical sample preparation session, $1 \mathrm{~g}$ of oxide was gradually mixed with $25 \mathrm{~mL}$ of a solution of acid. The samples were then aged at room temperature for $24 \mathrm{~h}$, dried and stored in a desiccator until its use in the TPD-MS experiment. Ethanol solutions were used to prepare samples of reaction series of aliphatic carboxylic acids $\mathrm{C} 2-\mathrm{C} 10$ on the $1 \mathrm{CeSi}$ surface. Aqueous solutions were used to prepare samples of deuterated acetic acid, nonlabeled acetic 
acid and ${ }^{13} \mathrm{C}$-labeled acetic acid on the hCeSi surface. Due to the fact that the deuterium atom of the hydroxyl group of the acid is subjected to very fast $\mathrm{H} / \mathrm{D}$ exchange in aqueous solutions; in fact, the impregnation was performed with $\mathrm{d} 3$-acetic acid $\left(\mathrm{D}_{3} \mathrm{CCOOH}\right)$. This is what we wanted to achieve, in order to eliminate the distortion of the results due to the rapid exchange of acidic hydrogen atoms of the carboxyl group.

\subsection{Temperature-Programmed Desorption Mass Spectrometry and Kinetic Parameters}

The experiments were performed in an electron ionization MKh-7304A monopole mass spectrometer (Sumy, Ukraine) adapted for temperature-programmed desorption [33]. Sample weighing $\sim 10 \mathrm{mg}$ was first placed in a molybdenum-quartz ampule $(5.4 \mathrm{~mm}$ in diameter, $20 \mathrm{~cm}$ in length, and $12 \mathrm{~mL}$ in volume) and evacuating to $\sim 5 \times 10^{-5} \mathrm{~Pa}$ at $\sim 20^{\circ} \mathrm{C}$. For all measurements, the molybdenum-quartz ampule was filled to only approximately $<<1 / 16$ of the full volume to limit interparticle-diffusion effects [43]. All TPD measurements were carried out by heating the samples to $\sim 750^{\circ} \mathrm{C}$ at a constant rate of $0.17^{\circ} \mathrm{C} \mathrm{s}^{-1}$ using a programmed linear heating schedule $(d T / d t=b$, in which $b$ is the heating rate). The mass spectra and the $\mathrm{P} / \mathrm{T}$ curves (pressure-temperature curves; $\mathrm{P}$, the pressure of volatile pyrolysis products; $\mathrm{T}$, the temperature of samples) were recorded and analyzed using a computer-based data acquisition and processing setup. The pressure of volatile pyrolysis products was measured with a pressure vacuum gauge VMB-14. The mass spectra were recorded for a mass range of 1-210 amu. The kinetic parameters (temperature of the maximum desorption rate $T_{\max }$, reaction order $n$, activation energy $E^{\neq}$, pre-exponential factor $v_{0}$ and activation entropy $d S^{\ddagger}$ ) were calculated from the well-resolved TPD peaks for which the shape and position on the temperature scale were repeated with good resolution in several measurements. The procedure of obtaining kinetic parameters from TPD-MS data and full details of this equipment has been extensively described elsewhere [43].

\section{Conclusions}

In this study, the applicability of TPD-MS together with LFERs for the elucidation of the mechanism of catalytic pyrolysis of carboxylic acids into ketones over $\mathrm{CeO}_{2} / \mathrm{SiO}_{2}$ was investigated. The kinetic parameters of catalytic pyrolysis of $\mathrm{C}_{\mathrm{n}} \mathrm{H}_{2 \mathrm{n}} \mathrm{COOH}(\mathrm{n}=1-9), \mathrm{CD}_{3} \mathrm{COOH}$, and $\mathrm{CH}_{3}{ }^{13} \mathrm{COOH}$ into ketones were calculated and analyzed. On their bases, the structure-reactivity correlation between Taft's steric substituent constants Es* and activation energies of catalytic ketonization for the reaction series of fatty acids on the surface of nanosized $\mathrm{CeO}_{2} / \mathrm{SiO}_{2}$ was obtained. This correlation shows that ketonization is a sterically sensitive reaction. The study of the pyrolysis kinetics of deuterated acetic acid on the $\mathrm{CeO}_{2} / \mathrm{SiO}_{2}$ surface showed that $\mathrm{H} / \mathrm{D}$ exchange starts at low temperature, $<150{ }^{\circ} \mathrm{C}$, and led to the formation layer of surface acetates isotopomers $-\mathrm{O}-\mathrm{C}(=\mathrm{O})-\mathrm{CD}_{\mathrm{n}} \mathrm{H}_{3-\mathrm{n}}$. It seems that $\mathrm{H}-\mathrm{D}$ exchange on the surface and the ketonization are two independent processes and isotopic exchange proceeds easily at temperatures lower than the temperature of the start of ketonization reaction. Surface acetates during heating transform into deuterated acetone isotopomers with different yield, $T_{\max }$, rate, $E^{\neq}$, and DKIE. Activation energy and DKIE decrease with increasing of D-atoms number in the acetone isotopomer molecule. The obtained values of inverse DKIE do not confirm enolization as a rate-limiting step of ketonization over $\mathrm{CeO}_{2} / \mathrm{SiO}_{2}$. Moreover, the obtained values of inverse DKIE together with the structure-reactivity correlation support the concerted mechanism involving the synchronous reorganization of bonds in the cyclic TS. A proposed simple equation (5) can be a useful tool for the elucidation of KIE values from TPD-MS data. Its applicability has been demonstrated on this experimental data.

Supplementary Materials: The following are available online at http://www.mdpi.com/2073-4344/10/2/179/s1, Figures S1-S5: Fitting of the TPD peaks for the molecular ion of acetone isotopomer with $\mathrm{m} / \mathrm{z}=58-62$ obtained during the pyrolysis of isotopic-labeled acetic acid $\mathrm{CD}_{3} \mathrm{COOH}$ on the hCeSi surface $\left(0.6 \mathrm{mmol} \cdot \mathrm{g}^{-1}\right)$. Figure S6: Fitting of the TPD peak for the molecular ion of acetone obtained during the pyrolysis of nonlabeled acetic acid $\mathrm{CH}_{3} \mathrm{COOH}$ on the hCeSi surface $\left(0.6 \mathrm{mmol} \cdot \mathrm{g}^{-1}\right)$. Figure S7: Fitting of the TPD peak for the molecular ion of acetone obtained during the pyrolysis of isotopic-labeled acetic acid $\mathrm{CH}_{3}{ }^{13} \mathrm{COOH}$ on the hCeSi surface $\left(0.6 \mathrm{mmol} \cdot \mathrm{g}^{-1}\right)$. 
Author Contributions: T.K. conducted samples preparation, results analysis, paper writing and project administration; B.P. conducted kinetics experiments; M.L. contributed to results discussion, editing of the paper and project administration. All authors have read and agreed to the published version of the manuscript.

Funding: This publication is based on work supported by the Swedish Research Council (VR, 348-2014-4250), by STCU (Grant P707), by the Volkswagen Foundation and by NAS of Ukraine (Program "New functional substances and materials of chemical production"). T.K. acknowledges the Swedish Institute for research scholarship for senior researchers within Visby Programme [03804/2016].

Acknowledgments: We are grateful to Borysenko M.V. and Kulyk K.S. for providing the $\mathrm{CeO}_{2} / \mathrm{SiO}_{2}$ samples.

Conflicts of Interest: The authors declare no conflict of interest.

\section{References}

1. Bridgwater, A.V. Review of fast pyrolysis of biomass and product upgrading. Biomass Bioenergy 2012, 38, 68-94. [CrossRef]

2. Kataki, R.; Chutia, R.S.; Mishra, M.; Bordoloi, N.; Saikia, R.; Bhaskar, T. Feedstock suitability for thermochemical processes. In Recent Advances in Thermo-Chemical Conversion of Biomass, 1st ed.; Pandey, A., Bhaskar, T., Stöcker, M., Sukumaran, R., Eds.; Elsevier: Amsterdam, The Netherlands, 2015; pp. 31-74.

3. Zhang, S.; Yang, X.; Zhang, H.; Chu, C.; Zheng, K.; Ju, M.; Liu, L. Liquefaction of biomass and upgrading of bio-oil: A review. Molecules 2019, 24, 2250. [CrossRef] [PubMed]

4. Lin, Y.C.; Huber, G.W. The critical role of heterogeneous catalysis in lignocellulosic biomass conversion. Energy Environ. Sci. 2009, 2, 68-80. [CrossRef]

5. Albrecht, K.O.; Olarte, M.V.; Wang, H. Upgrading Fast Pyrolysis Liquids. In Thermochemical Processing of Biomass: Conversion into Fuels, Chemicals and Power, 2nd ed.; Brown, R.C., Ed.; Wiley Online Library: Hoboken, NJ, USA, 2019. [CrossRef]

6. Sheldon, R.A. Green chemistry, catalysis and valorization of waste biomass. J. Mol. Catal. A Chem. 2016, 422, 3-12. [CrossRef]

7. Climent, M.J.; Corma, A.; Iborra, S. Conversion of biomass platform molecules into fuel additives and liquid hydrocarbon fuels. Green Chem. 2014, 16, 516-547. [CrossRef]

8. De Wit, M.; Faaij, A. European biomass resource potential and costs. Biomass Bioenergy 2010, 34, $188-202$. [CrossRef]

9. Nanda, S.; Mohanty, P.; Kozinski, J.A.; Dalai, A.K. Hydrothermal and Thermochemical Synthesis of Bio-Oil from Lignocellulosic Biomass: Composition, Engineering and Catalytic Upgrading. In Industrial Biotechnology, 1st ed.; Thangadurai, D., Sangeetha, J., Eds.; Apple Academic Press: New York, NY, USA, 2017; pp. 345-390.

10. Nanda, S.; Mohanty, P.; Kozinski, J.A.; Dalai, A.K. Physico-Chemical Properties of Bio-Oils from Pyrolysis of Lignocellulosic Biomass with High and Slow Heating Rate. Energy Environ. Res. 2014, 21, 21-32. [CrossRef]

11. Novakovskiy, D.J.; Jones, J.M. Uncatalysed and potassium-catalysed pyrolysis of the cell-wall constituents of biomass and their model compounds. J. Anal. Appl. Pyrol. 2008, 83, 12-25.

12. Serrano-Ruiz, J.C.; Braden, D.J.; West, R.M.; Dumesic, J.A. Conversion of cellulose to hydrocarbon fuels by progressive removal of oxygen. Appl. Catal. B 2010, 100, 184-189. [CrossRef]

13. Zhang, Y.; Cui, H.; Yi, W.; Song, F.; Zhao, P.; Wang, L.; Cui, J. Highly effective decarboxylation of the carboxylic acids in fast pyrolysis oil of rice husk towards ketones using $\mathrm{CaCO}_{3}$ as a recyclable agent. Biomass Bioenergy 2017, 102, 13-22. [CrossRef]

14. Lange, J.P.; Price, R.; Ayoub, P.M.; Louis, J.; Petrus, L.; Clarke, L.; Gosselink, H. Valeric Biofuels: A Platform of Cellulosic Transportation Fuels. Angew. Chem. Int. Ed. 2010, 49, 4479-4483. [CrossRef] [PubMed]

15. Jiang, B.; Xi, Z.; Lu, F.; Huang, Z.; Yang, Y.; Sun, J.; Liao, Z.; Wang, J.; Yang, Y. Ce/MgAl mixed oxides derived from hydrotalcite LDH precursors as highly efficient catalysts for ketonization of carboxylic acid. Catal. Sci. Technol. 2019, 9, 6335-6344. [CrossRef]

16. Ling, H.; Wang, Z.; Wang, L.; Stampfl, C.; Wang, D.; Chen, J.; Huang, J. Composition-structure-function correlation of $\mathrm{Ca} / \mathrm{Zn} / \mathrm{AlOx}$ catalysts for the ketonization of acetic acid. Catal. Today 2019. [CrossRef]

17. Ignatchenko, A.V. Multiscale approach for the optimization of ketones production from carboxylic acids by the decarboxylative ketonization reaction. Catal. Today 2019, 338, 3-17. [CrossRef] 
18. Psarras, A.C.; Michailof, C.M.; Iliopoulou, E.F.; Kalogiannis, K.G.; Lappas, A.A.; Heracleous, E.; Triantafyllidis, K.S. Acetic acid conversion reactions on basic and acidic catalysts under biomass fast pyrolysis conditions. J. Mol. Catal. 2019, 465, 33-42. [CrossRef]

19. Pham, T.N.; Sooknoi, T.; Crossley, S.P.; Resasco, D.E. Ketonization of carboxylic acids: Mechanisms, catalysts, and implications for biomass conversion. ACS Catal. 2013, 3, 2456-2473. [CrossRef]

20. Renz, M. Ketonization of carboxylic acids by decarboxylation: Mechanism and scope. Eur. J. Org. Chem. 2005, 6, 979-988. [CrossRef]

21. Kumar, R.; Enjamuri, N.; Shah, S.; Al-Fatesh, A.S.; Bravo-Suárez, J.J.; Chowdhury, B. Ketonization of oxygenated hydrocarbons on metal oxide based catalysts. Catal. Today 2018, 302, 16-49. [CrossRef]

22. Dooley, K.M. Catalysis of acid/aldehyde/alcohol condensations to ketones. Catalysis 2004, 17, $293-319$.

23. Simakova, I.L.; Murzin, D.Y. Transformation of bio-derived acids into fuel-like alkanes via ketonic decarboxylation and hydrodeoxygenation: Design of multifunctional catalyst, kinetic and mechanistic aspects. J. Energy Chem. 2017, 25, 208-224. [CrossRef]

24. Hites, R.A.; Biemann, K. Mechanism of ketonic decarboxylation. Pyrolysis of calcium decanoate. J. Am. Chem. Soc. 1972, 94, 5772-5777. [CrossRef]

25. Rand, L.; Wagner, W.; Warner, P.O.; Kovac, L.R. Reactions catalyzed by potassium fluoride. II. The conversion of adipic acid to cyclopentanone. J. Org. Chem. 1962, 27, 1034-1035. [CrossRef]

26. Gumidyala, A.; Sooknoi, T.; Crossley, S. Selective ketonization of acetic acid over HZSM-5: The importance of acyl species and the influence of water. J. Catal. 2016, 340, 76-84. [CrossRef]

27. Hendren, T.S.; Dooley, K.M. Kinetics of catalyzed acid/acid and acid/aldehyde condensation reactions to non-symmetric ketones. Catal. Today 2003, 85, 333-351. [CrossRef]

28. Pestman, R.; Koster, R.M.; van Duijne, A.; Pieterse, J.A.Z.; Ponec, V. Reactions of Carboxylic Acids on Oxides. 2. Bimolecular Reaction of Aliphatic Acids to Ketones. J. Catal. 1997, 168, 265-272. [CrossRef]

29. González, F.; Munuera, G.; Prieto, J.A. Mechanism of Ketonization of Acetic Acid on Anatase Ti02 Surfaces. J. Chem. Soc. Faraday Trans. 1978, 74, 1517-1529. [CrossRef]

30. Pulido, A.; Oliver-Tomas, B.; Renz, M.; Boronat, M.; Corma, A. Ketonic decarboxylation reaction mechanism: A combined experimental and DFT study. ChemSusChem 2013, 6, 141-151. [CrossRef]

31. Pham, T.N.; Shi, D.; Resasco, D.E. Kinetics and Mechanism of Ketonization of Acetic Acid on Ru/TiO 2 Catalyst. Top. Catal. 2014, 57, 706-714. [CrossRef]

32. Ignatchenko, A.V.; McSally, J.P.; Bishop, M.D.; Zweigle, J. Ab initio study of the mechanism of carboxylic acids cross-ketonization on monoclinic zirconia via condensation to beta-keto acids followed by decarboxylation. J. Mol. Catal. 2017, 441, 35-62. [CrossRef]

33. Ignatchenko, A.V.; Kozliak, E.I. Distinguishing enolic and carbonyl components in the mechanism of carboxylic acid ketonization on monoclinic zirconia. ACS Catal. 2012, 2, 1555-1562. [CrossRef]

34. Ignatchenko, A.V.; Cohen, A.J. Reversibility of the catalytic ketonization of carboxylic acids and of beta-keto acids decarboxylation. Catal. Commun. 2018, 111, 104-107. [CrossRef]

35. Oliver-Tomas, B.; Renz, M.; Corma, A. Ketone formation from carboxylic acids by Ketonic decarboxylation: The exceptional case of the tertiary carboxylic acids. Chem. Eur. J. 2017, 23, 12900-12908. [CrossRef] [PubMed]

36. Wang, S.; Iglesia, E. Experimental and theoretical assessment of the mechanism and site requirements for ketonization of carboxylic acids on oxides. J. Catal. 2017, 345, 183-206. [CrossRef]

37. Ding, S.; Zhao, J.; Yu, Q. Effect of Zirconia Polymorph on Vapor-Phase Ketonization of Propionic Acid. Catalysts 2019, 9, 768. [CrossRef]

38. Nagashima, O.; Sato, S.; Takahashi, R.; Sodesawa, T. Ketonization of carboxylic acids over $\mathrm{CeO}_{2}$-based composite oxides. J. Mol. Catal. A Chem. 2005, 227, 231-239. [CrossRef]

39. Almutairi, S.T.; Kozhevnikova, E.F.; Kozhevnikov, I.V. Ketonisation of acetic acid on metal oxides: Catalyst activity, stability and mechanistic insights. Appl. Catal. A 2018, 565, 135-145. [CrossRef]

40. Hasan, M.A.; Zaki, M.I.; Pasupulety, L. Oxide-catalyzed conversion of acetic acid into acetone: An FTIR spectroscopic investigation. Appl. Catal. A 2003, 243, 81-92. [CrossRef]

41. Kulyk, K.; Palianytsia, B.; Alexander, J.D.; Azizova, L.; Borysenko, M.; Kartel, M.; Larsson, M.; Kulik, T. Kinetics of valeric acid ketonization and ketenization in catalytic pyrolysis on nanosized $\mathrm{SiO}_{2}, \gamma-\mathrm{Al}_{2} \mathrm{O}_{3}$, $\mathrm{CeO}_{2} / \mathrm{SiO}_{2}, \mathrm{Al}_{2} \mathrm{O}_{3} / \mathrm{SiO}_{2}$ and $\mathrm{TiO}_{2} / \mathrm{SiO}_{2}$. ChemPhysChem 2017, 18, 1943-1955. [CrossRef] 
42. Anslyn, E.V.; Dougherty, D.A. Modern Physical Organic Chemistry; University Science Books: Sausalito, CA, USA, 2006. [CrossRef]

43. Kulik, T.V. Use of TPD-MS and linear free energy relationships for assessing the reactivity of aliphatic carboxylic acids on a silica surface. J. Phys. Chem. C 2012, 116, 570-580. [CrossRef]

44. Dupre, G.D.; Schlosberg, R.H.; Pancirov, R.J.; Ashe, T.R.; Baset, Z. Pyrolysis studies of organic oxygenates VI. thermal Chemistry of long chain aliphatic acids. Liq. Fuels Technol. 1985, 3, 323-344. [CrossRef]

45. Kim, K.S.; Barteau, M.A. Pathways for carboxylic acid decomposition on titania. Langmuir 1988, 4, 945-953. [CrossRef]

46. García-Sánchez, M.; Sales-Cruz, M.; Lopez-Arenas, T.; Viveros-García, T.; Pérez-Cisneros, E.S. An Intensified Reactive Separation Process for Bio-Jet Diesel Production. Processes 2019, 7, 655. [CrossRef]

47. Martinez, R.; Huff, M.C.; Barteau, M.A. Synthesis of ketenes from carboxylic acids on functionalized silica monoliths at short contact time. Appl. Catal. A 2000, 200,79-88. [CrossRef]

48. Libby, M.C.; Watson, P.C.; Barteau, M.A. Synthesis of Ketenes with oxide catalysts. Ind. Eng. Chem. Res. 1994, 33, 2904-2912. [CrossRef]

49. Azizova, L.R.; Kulik, T.V.; Palyanytsya, B.B.; Lipkovska, N.A. Thermal and hydrolytic stability of grafted ester groups of carboxylic acids on the silica surface. J. Therm. Anal. Calorim. 2015, 122, 517-523. [CrossRef]

50. Brei, V.V.; Brichka, A.V. A Study of the Brönsted Site Acidity of Crystalline and Amorphous Aluminosilicates: 2. Thermal Decomposition of Grafted Acetyl Groups. Adsorp. Sci. Technol. 1996, 14, 359-362. [CrossRef]

51. Kulik, T.V.; Barvinchenko, V.N.; Palyanitsa, B.B.; Smirnova, O.V.; Pogorelyi, V.K.; Chuiko, A.A. A desorption mass spectrometry study of the interaction of cinnamic acid with a silica surface. Russ. J. Phys. Chem. 2007, 8, 83-90. [CrossRef]

52. Kulik, T.V.; Lipkovska, N.A.; Barvinchenko, V.N.; Palyanytsya, B.B.; Kazakova, O.A.; Dovbiy, O.A.; Pogorelyi, V.K. Interactions between bioactive ferulic acid and fumed silica by UV-vis spectroscopy, FT-IR, TPD MS investigation and quantum chemical methods. J. Colloid Interface Sci. 2009, 339, 60-68. [CrossRef]

53. Kulik, T.V.; Lipkovska, N.O.; Barvinchenko, V.M.; Palyanytsya, B.B.; Kazakova, O.A.; Dudik, O.O.; Menyhárd, A.; László, K. Thermal transformation of bioactive caffeic acid on fumed silica seen by UV-Vis spectroscopy, thermogravimetric analysis, temperature programmed desorption mass spectrometry and quantum chemical methods. J. Colloid Interface Sci. 2016, 470, 132-141. [CrossRef]

54. Nastasiienko, N.; Palianytsia, B.; Kartel, M.; Larsson, M.; Kulik, T. Thermal transformation of caffeic acid on the nanosized cerium dioxide studied by temperature programmed desorption mass-spectrometry, thermogravimetric analysis and FTIR-spectroscopy. Colloids Interfaces 2019, 3, 34. [CrossRef]

55. Vlasenko, N.V.; Kyriienko, P.I.; Yanushevska, O.I.; Valihura, K.V.; Soloviev, S.O.; Strizhak, P.E. The Effect of Ceria Content on the Acid-Base and Catalytic Characteristics of $\mathrm{ZrO}_{2}-\mathrm{CeO}_{2}$ Oxide Compositions in the Process of Ethanol to n-Butanol Condensation. Catal. Lett. 2019, 1-9. [CrossRef]

56. Vivier, L.; Duprez, D. Ceria-Based Solid Catalysts for Organic Chemistry. ChemSusChem 2010, 3, $654-678$. [CrossRef] [PubMed]

57. Wu, Z.; Mann, A.K.; Li, M.; Overbury, S.H. Spectroscopic investigation of surface-dependent acid-base property of ceria nanoshapes. J. Phys. Chem. 2015, C 119, 7340-7350. [CrossRef]

58. Wu, Z.; Li, M.; Mullins, D.R.; Overbury, S.H. Probing the surface sites of $\mathrm{CeO} 2$ nanocrystals with well-defined surface planes via methanol adsorption and desorption. ACS Catal. 2012, 2, 2224-2234. [CrossRef]

59. Martin, D.; Duprez, D. Evaluation of the acid-base surface properties of several oxides and supported metal catalysts by means of model reactions. J. Mol. Catal. A Chem. 1997, 118, 113-128. [CrossRef]

60. Binet, C.; Daturi, M.; Lavalley, J.C. IR study of polycrystalline ceria properties in oxidised and reduced states. Catal. Today 1999, 50, 207-225. [CrossRef]

61. Calaza, F.C.; Chen, T.L.; Mullins, D.R.; Xu, Y.; Overbury, S.H. Reactivity and reaction intermediates for acetic acid adsorbed on CeO2 (111). Catal. Today 2015, 253, 65-76. [CrossRef]

62. Stein, E. NIST Chemistry WebBook. IR and Mass Spectra, Database Number 69; Mallard, W.G., Linstrom, P.J., Eds.; National Institute of Standards and Technology: Gaithersburg, MD, USA, 2000.

63. Gliński, M.; Kijeński, J.; Jakubowski, A. Ketones from monocarboxylic acids: Catalytic ketonization over oxide systems. Appl. Catal. A Gen. 1995, 128, 209-217. [CrossRef]

64. Deng, L.; Fu, Y.; Guo, Q.X. Upgraded acidic components of bio-oil through catalytic ketonic condensation. Energy Fuels 2008, 23, 564-568. [CrossRef] 
65. Woodruff, D.P.; Delchar, T.A. Modern Techniques of Surface Science; Cambridge University Press: London, UK, 1986. [CrossRef]

66. Redhead, P.A. Thermal Desorption of Gases. Vacuum 1962, 12, 203-211. [CrossRef]

67. Kislyuk, M.U.; Rozanov, V.V. Temperature-programmed desorption and temperature-programmed reaction methods of studying of kinetics and mechanisms of catalytic processes. Kinet. Catal. 1995, 36, 89-98.

68. Carter, G. Thermal resolution of desorption energy spectra. Vacuum 1962, 12, 245-254. [CrossRef]

69. Leardini, F.; Fernández, J.F.; Bodega, J.; Sanchez, C. Isotope effects in the kinetics of simultaneous H and D thermal desorption from Pd. J. Phys. Chem. Solid 2008, 69, 116-127. [CrossRef]

70. Houk, K.N.; Gustafson, S.M.; Black, K.A. Theoretical secondary kinetic isotope effects and the interpretation of transition state geometries. 1. The Cope rearrangement. J. Am. Chem. Soc. 1992, 114, 8565-8572. [CrossRef]

71. Hoque, M.E.U.; Guha, A.K.; Kim, C.K.; Lee, B.S.; Lee, H.W. Concurrent primary and secondary deuterium kinetic isotope effects in anilinolysis of O-aryl methyl phosphonochloridothioates. Org. Biomol. Chem. 2009, 7, 2919-2925. [CrossRef]

72. Borysenko, M.V.; Kulyk, K.S.; Ignatovych, M.V.; Poddenezhny, E.N.; Boiko, A.A.; Dobrodey, A.O. Sol-gel synthesis of silica glasses, doped with nanoparticles of cerium oxide. In Nanomaterials and Supramolecular Structures; Shpak, A.P., Gorbyk, P.P., Eds.; Springer: Dordrecht, The Netherlands, 2009; pp. 227-233. [CrossRef]

(C) 2020 by the authors. Licensee MDPI, Basel, Switzerland. This article is an open access article distributed under the terms and conditions of the Creative Commons Attribution (CC BY) license (http://creativecommons.org/licenses/by/4.0/). 